\title{
AVALIAÇÃO E GESTÃO DOS RISCOS NÃO COMPROVADOS: ESTUDO DE CASOS DA APLICAÇÃO DO PRINCÍPIO DA PRECAUÇÃO EM PORTUGAL
}

Vasco Gonçalves

Dezembro 2017

WP n. $02017 / 05$

DOCUMENTO DE TRABALHO

WORKING PAPER

\section{ISCTE IUL}

Instituto Universitário de Lisboa 


\title{
AVALIAÇÃO E GESTÃO DOS RISCOS NÃO COMPROVADOS: ESTUDO DE CASOS DA APLICAÇÃO DO PRINCÍPIO DA PRECAUÇÃO \\ EM PORTUGAL
}

\author{
Vasco Gonçalves * \\ WP n. $\circ$ 2017/05
}

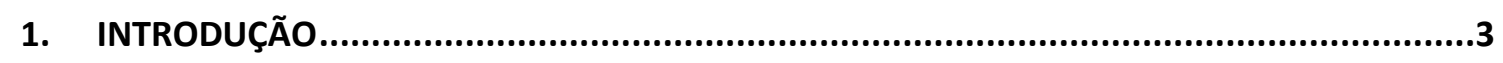

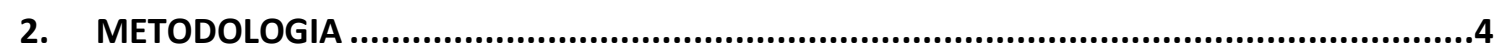

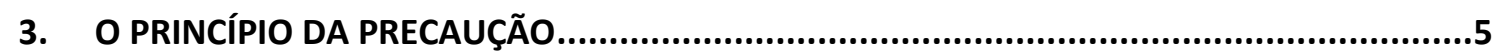

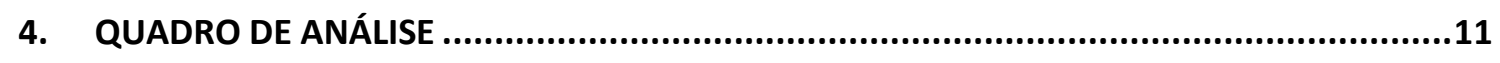

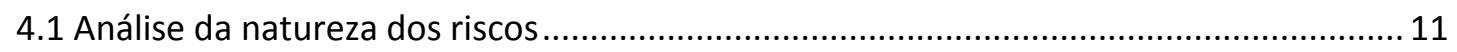

4.2. Análise do nível de exigência de prova .................................................................... 13

4.3. Análise da severidade das medidas de precaução ...................................................... 15

4.4. Análise da proporcionalidade das medidas de precaução ............................................ 16

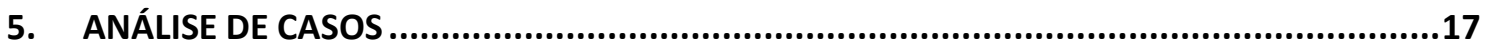

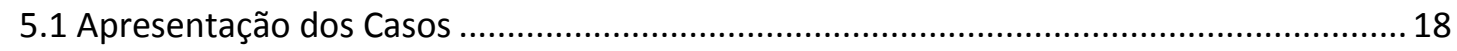

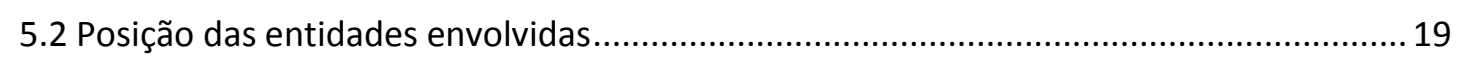

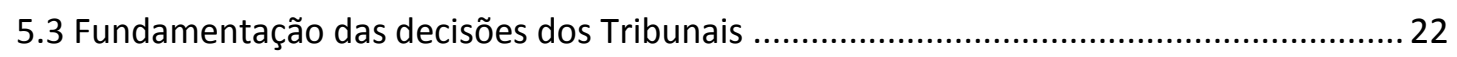

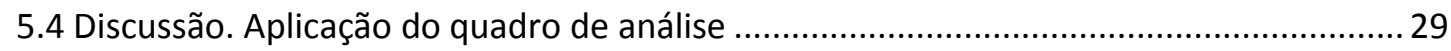

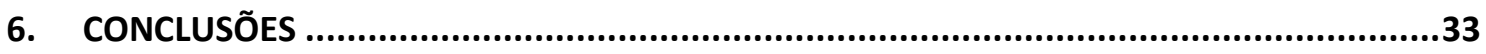

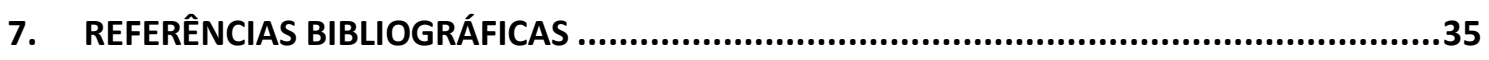

*Instituto Universitário de Lisboa (ISCTE-IUL), DINÂMIA'CET-IUL, Lisboa, Portugal. 


\title{
AVALIAÇÃO E GESTÃO DOS RISCOS NÃO COMPROVADOS: ESTUDO DE CASOS DA APLICAÇÃO DO PRINCÍPIO DA PRECAUÇÃO EM PORTUGAL
}

\begin{abstract}
A aplicação do princípio da precaução na avaliação e na gestão dos riscos caracterizados por elevados níveis de incerteza científica e de gravidade dos danos potenciais para a saúde pública ou para o ambiente tem sido marcada por alguma ambiguidade na interpretação do conceito de precaução, pela insuficiente caracterização dos efeitos das atividades económicas e pela falta de mecanismos e de quadros operacionais de apoio à decisão. Isto tem dificultado o funcionamento da justiça administrativa e gerado discricionariedade, ambiguidade e imprevisibilidade quanto ao sentido das decisões. Neste artigo, pretende-se esclarecer o modo como o princípio da precaução tem sido interpretado e aplicado pelos tribunais em Portugal e contribuir para o debate sobre quando e como aplicar medidas de precaução na avaliação e na gestão dos riscos ambientais. Para isso, considera-se um conjunto recente de processos judiciais relevantes em áreas de atividade envolvendo riscos ambientais e para a saúde pública em que é considerada a aplicação do princípio da precaução, e analisam-se as decisões dos tribunais nas várias instâncias judiciais e a respectiva fundamentação. Com o objetivo de avaliar o grau de consistência da aplicação da precaução em relação à análise de riscos comparáveis e a proporcionalidade das decisões face à gravidade dos riscos é desenvolvido um quadro teórico de análise baseado em três atributos: natureza dos riscos, nível de exigência de prova, nível de severidade das medidas aplicadas. O estudo efectuado permite constatar as posições diferenciadas entre os tribunais com argumentos contraditórios perante o mesmo caso ou perante casos semelhantes, reconhecendo os perigos mas atribuindo-lhes diferentes níveis de gravidade, exigindo diferentes níveis de prova ou dando prioridade a diferentes interesses. Parece assim ser desejável que a regulamentação do princípio da precaução possa vir a dispor de requisitos e de critérios mais explícitos quanto ao esclarecimento sobre os riscos e a ponderação de interesses, nas diferentes áreas de actividade, e quanto à proporcionalidade das decisões. Neste contexto, será muito importante que os tribunais possam dispor do apoio técnico e de orientação de uma expertise científica de qualidade relativamente à análise da informação ambiental e económica.
\end{abstract}

PALAVRAS-CHAVE: avaliação e gestão dos riscos ambientais; princípio da precaução; casos judiciais

DINÂMIA'CET - IUL, Centro de Estudos sobre a Mudança Socioeconómica e o Território

do Instituto Universitário de Lisboa (ISCTE-IUL)

Sala 2W4 - D | ISCTE-IUL - Av. das Forças Armadas

1649-026 Lisboa, PORTUGAL

Tel. (+351) 210464031 - Extensão 293101 | E-mail: dinamia@iscte-iul.pt | www.dinamiacet.iscte-iul.pt 


\section{INTRODUÇÃ̃}

A aplicação do princípio da precaução na avaliação e na gestão dos riscos complexos, tecnológicos e emergentes, caracterizados por elevados níveis de incerteza científica e de gravidade dos danos potenciais para a saúde pública ou para o ambiente, tem sido marcada por alguma ambiguidade na interpretação do conceito de precaução, pela insuficiente caracterização dos efeitos das atividades económicas e pela falta de mecanismos e de quadros operacionais de apoio à decisão.

A diversidade de situações, a inexistência de normativos precisos, os interesses múltiplos (ambientais, económicos e sociais) para ponderar, dificultam o papel do decisor, para mais num quadro de incerteza. Nas disputas em tribunal, em particular, os juízes sentem dificuldades na apreciação de factos apresentados segundo a perspectiva de outros ramos da ciência e da técnica que não o direito.

Por isso, as condições da aplicação do princípio da precaução têm sido muito condicionadas por factores como os objetivos dos decisores, as suas atitudes face ao risco e as regras e critérios de decisão que utilizam, dificultando o funcionamento da justiça administrativa e gerando discricionariedade, ambiguidade e imprevisibilidade quanto ao sentido das decisões.

Neste artigo, pretende-se esclarecer o modo como o princípio da precaução tem sido interpretado e aplicado pelos tribunais em Portugal na análise de conflitos associados à existência de perigos incertos para o ambiente ou para a saúde pública.

Para isso, considera-se um conjunto recente de dez processos judiciais relevantes, relativos a ações em áreas de atividade envolvendo riscos ambientais e para a saúde pública, e em que é considerada a aplicação do princípio da precaução, e analisam-se as decisões dos tribunais nas várias instâncias judiciais e a respectiva fundamentação.

Com o objetivo de avaliar o grau de consistência da aplicação da precaução em relação à análise de riscos comparáveis e a proporcionalidade das decisões dos diferentes tribunais face à gravidade dos riscos é desenvolvido um quadro teórico de análise baseado em três atributos: natureza dos riscos (gravidade do perigo potencial), nível de exigência de prova, nível de severidade das medidas aplicadas.

Pretende-se, finalmente, contribuir para o debate sobre quando e como aplicar medidas de precaução e para a melhoria das condições de aplicação deste princípio na avaliação e na gestão dos riscos ambientais.

DINÂMIA'CET - IUL, Centro de Estudos sobre a Mudança Socioeconómica e o Território

do Instituto Universitário de Lisboa (ISCTE-IUL)

Sala 2W4 - D | ISCTE-IUL - Av. das Forças Armadas

1649-026 Lisboa, PORTUGAL

Tel. (+351) 210464031 - Extensão 293101 | E-mail: dinamia@iscte-iul.pt | www.dinamiacet.iscte-iul.pt 


\section{METODOLOGIA}

Este artigo apresenta um estudo empírico de natureza qualitativa a partir de uma análise de um conjunto de casos de estudo com o objetivo de descrever as suas características e as circunstâncias e juízos que fundamentam as decisões de aplicação do princípio da precaução aos diferentes casos.

Depois de uma apresentação inicial, no Capítulo 3, sobre o princípio da precaução, referindo o conceito, os principais elementos, as tendências recentes e as perspectivas futuras da sua aplicação, descreve-se, no Capítulo 4, o quadro de análise que foi desenvolvido, a partir da literatura teórica e empírica, com o objectivo de permitir a análise sistemática dos casos de estudo quanto à interpretação e à aplicação do princípio da precaução pelos tribunais. Este quadro, baseado em atributos do princípio da precaução, procura também esclarecer a consistência ou não da sua aplicação nos diferentes casos, reflectindo em particular o contexto da decisão (área de atividade, gravidade do risco, decisão tomada).

A selecção dos casos considerados relevantes para o estudo foi realizada a partir de uma pesquisa na Base de Dados do Ministério da Justiça.

Estes casos são apresentados e analisados no Capítulo 5. Nesta análise é considerada a fundamentação das posições das partes envolvidas e das decisões dos tribunais nas várias instâncias de decisão e é avaliada a extensão com que o pensamento e as acções de precaução foram aplicados na prática. São exploradas as similitudes e as diferenças entre os diferentes casos.

Finalmente, no Capítulo 6, a partir dos resultados obtidos neste estudo quanto ao modo como os tribunais lidam com os riscos não comprovados em Portugal, conclui-se com a recomendação de medidas regulamentares destinadas à melhoria das condições de aplicação do princípio da precaução na avaliação e na gestão dos riscos ambientais. 


\section{O PRINCÍPIO DA PRECAUÇÃO}

\section{Conceito e principais elementos}

O princípio da precaução é presentemente um princípio fundamental da regulação ambiental em muitos países.

Surge no contexto da estratégia de gestão de riscos em domínios em que as medidas que permitem atingir o objectivo de uma protecção elevada, nomeadamente em matéria de ambiente e de saúde, não podem ser determinadas com uma base de certeza científica, admitindo-se que possam causar danos elevados ou mesmo irreversíveis para o ambiente e a saúde pública (OCDE, 2003; Stirling, 2007; Renn, 2008; CPP, 2010).

As situações de precaução correspondem a cenários de risco nos quais um elemento da cadeia causal que vai do perigo aos efeitos finais é incerto, no sentido em que a relação de causa-efeito sobre a qual se basearia esse elemento não pode ser estabelecida nem rejeitada. Contrariamente às situações de riscos simples (ou comprovados), que é possível prevenir, com base no conhecimento científico, trata-se aqui de situações complexas, onde os riscos são multicausais e envolvidos em incerteza e/ou ambiguidade (Renn, 2008). Exemplos são os campos eletromagnéticos (telemóveis e antenas de telemóveis) e a sua relação com certos cancros, os nanomateriais e os seus efeitos específicos e massivos sobre as populações ou os efeitos de alterações ambientais sobre a biodiversidade (SEHN, 2009; CPP, 2010; Rogers, 2011).

Tem-se assistido, com efeito, em relação a este tipo de riscos, a uma transição na política ambiental de uma tomada de decisão reactiva para uma gestão ambiental pró - activa, contribuindo o princípio da precaução para a base conceptual e legal dessa transição.

O princípio da precaução encontra-se inserido na legislação europeia ${ }^{1}$ (em Programas de Ação, diretivas, declarações e recomendações), com incidência no direito interno ao nível dos Estados-Membros (na legislação nacional, regional e local). Nos EUA, programas e medidas de precaução são aplicados no nível estadual e no nível local e, embora não seja citada expressamente na legislação e nas políticas federais, a presença do princípio da precaução está subjacente à natureza de grande parte da legislação ambiental. Encontra-se ainda expressamente citado em conferências e tratados internacionais como a Conferência das Nações Unidas sobre Ambiente e Desenvolvimento (Cimeira do Rio) (1992) ou a Convenção sobre a Biodiversidade

\footnotetext{
${ }^{1}$ Foi inserido no artigo $130 \mathrm{R}$ (2) do Tratado de Maastricht (1992), actual artigo 191, parágrafo 2 do Tratado da União Europeia. A referência explícita ao princípio da precaução é a seguinte: "A politica de ambiente da União Europeia (...) será baseada nos princípios da precaução e da acção preventiva, da correcção, prioritariamente na fonte, dos danos causados ao ambiente e do poluidor-pagador".
}

DINÂMIA'CET - IUL, Centro de Estudos sobre a Mudança Socioeconómica e o Território

do Instituto Universitário de Lisboa (ISCTE-IUL)

Sala 2W4 - D | ISCTE-IUL - Av. das Forças Armadas 1649-026 Lisboa, PORTUGAL

Tel. (+351) 210464031 - Extensão 293101 | E-mail: dinamia@iscte-iul.pt | www.dinamiacet.iscte-iul.pt 


\section{Avaliação e gestão dos riscos não comprovados: \\ Estudo de casos da aplicação do princípio da precaução em Portugal}

(2000) (UNCED, 1992; Secretariat of the Convention on Biological Diversity, 2000) e em outros instrumentos de Direito Internacional, como na legislação do comércio internacional.

São variadas as formulações existentes para o princípio da precaução, com diferentes níveis de exigência de ações de intervenção, mais impositivas de obrigações em alguns casos e mais concedentes de possibilidade aos decisores para agirem com precaução em outros. De qualquer modo, um princípio legal geralmente não determinará a realização de uma decisão ou acção específica, mas apenas imporá um dado procedimento em certos casos.

Uma das definições mais representativas é a da Declaração da Cimeira do Rio, no seu princípio 15: "De modo a proteger o meio ambiente, o princípio da precaução deve ser amplamente observado pelos Estados, de acordo com suas capacidades. Quando houver ameaça de danos sérios ou irreversíveis sobre o ambiente, a ausência de absoluta certeza cientifica não deve ser utilizada como razão para adiar medidas custo - eficazes para prevenir a degradação ambiental" (UNCED, 1992).

Uma outra formulação é a da Comunicação da União Europeia sobre o Princípio da Precaução (CE, 2000), segundo a qual este princípio deverá ser invocado "quando as informações científicas são incompletas, pouco conclusivas ou incertas e quando os dados existentes sugerem, com fundamentos de razoabilidade, efeitos possíveis sobre o ambiente ou a saúde potencialmente perigosos e incompatíveis com o nível de protecção desejado." Esta Comunicação esclarece ainda que as medidas de precaução deverão satisfazer os critérios de proporcionalidade em relação ao nível de protecção requerido, de não discriminação, de consistência com outras medidas, com base na análise dos benefícios e custos potenciais, e serem sujeitas a revisão quando surgem novos dados científicos e capazes de atribuir responsabilidade pela produção das provas científicas necessárias.

Uma outra formulação ainda, a declaração de Wingspread (SEHN, 1998), alargou o âmbito do princípio da precaução a "ameaças de perigo para a saúde humana ou o ambiente", retirando a qualificação de "severidade" do perigo. Incluiu ainda uma referência explícita à inversão do ónus da prova para o proponente da atividade.

Apesar de crescentemente aceite como princípio geral de política, direito e gestão ambiental, na prática o princípio da precaução tem tido uma aplicação marcada pela controvérsia e pelo debate, em particular em situações onde pode ser considerado como restrição à atividade económica e ao comércio (como no contexto da OMC ou da bio segurança). Factores económicos, políticos, sociais e culturais e a complexidade dos interesses em presença têm condicionado a extensão da atenção dada, em diferentes países, a estratégias

DINÂMIA'CET - IUL, Centro de Estudos sobre a Mudança Socioeconómica e o Território

do Instituto Universitário de Lisboa (ISCTE-IUL)

Sala 2W4 - D | ISCTE-IUL - Av. das Forças Armadas

1649-026 Lisboa, PORTUGAL

Tel. (+351) 210464031 - Extensão 293101 | E-mail: dinamia@iscte-iul.pt | www.dinamiacet.iscte-iul.pt 
de precaução pela legislação e pelas instituições (Randall, 2009; Wiener et al., 2011; Lofstedt, $2014)^{2}$.

Esta controvérsia resulta também de alguma ambiguidade existente na definição do próprio princípio da precaução, em termos como a "ameaça de danos sérios ou irreversíveis" sobre o ambiente ou a "ausência de absoluta certeza científica" e é função da dificuldade da identificação e análise das incertezas e da falta de orientação para a aplicação de medidas de precaução adequadas, em contextos sectoriais muito diversos.

No entanto, a maior parte das formulações tem elementos chave comuns e a comunidade científica e os decisores políticos não divergem no essencial na identificação das principais questões a considerar na implementação prática da precaução, a saber: qual o nível de risco ambiental requerido para aplicar o princípio; qual a relevância das consequências potenciais da actividade com risco; qual o nível de severidade que as medidas de precaução deverão ter ${ }^{3}$. A resposta a este conjunto de questões traduz efetivamente a integração da análise, da avaliação e da gestão dos riscos não comprovados.

A questão do nível de severidade das medidas de precaução traduz a dificuldade na selecção dos resultados requeridos para a decisão de precaução, que poderão ir desde a proibição de actividades com risco até que sejam esclarecidas as incertezas existentes até à aplicação de estratégias adaptativas, como a implementação de medidas de minimização de impactes negativos, de monitorização ou de vigilância ou a simples realização de estudos de aprofundamento do conhecimento científico sobre os riscos (Peel, 2009; Stirling, 2017). As medidas de precaução deverão ser adequadas à gravidade das consequências potenciais dos riscos incorridos, num contexto de proporcionalidade que requer a definição da natureza específica dos riscos e do nível de segurança requerido.

Em Portugal, a Constituição reconhece direitos fundamentais em matéria de saúde pública e ambiente, mas o princípio da precaução não tem assento explícito na Constituição, ao contrário do princípio da prevenção (art. 66 $6^{\circ} \mathrm{n}^{\circ} 1$ ) (Gomes, 2013). O princípio da precaução

\footnotetext{
${ }^{2}$ Muitos estudos, de natureza conceptual ou empírica, têm sido dedicados ao princípio da precaução e questões relacionadas, em diversos domínios científicos, como o direito internacional, a ciência política, a economia ecológica e a governação ambiental (Myers e Raffensperger, 2005; De Sadeleer, 2006; Stirling, 2017; Renn et al., 2009; Zander, 2010; Iverson e Perrings, 2012).

${ }^{3} \mathrm{~A}$ EEA considera que a maior parte das questões relativas à precaução são objeto de acordo europeu ou internacional, embora com exigências diferentes entre os EUA e a Europa em certos domínios. Por isso, os objetivos da precaução não induzem desvios de competitividade significativos entre os países desenvolvidos. Aliás, estudos demonstram que a precaução é em geral mais rentável do que a inacção (EEA, 2013).
}

DINÂMIA'CET - IUL, Centro de Estudos sobre a Mudança Socioeconómica e o Território do Instituto Universitário de Lisboa (ISCTE-IUL)

Sala 2W4 - D | ISCTE-IUL - Av. das Forças Armadas 1649-026 Lisboa, PORTUGAL 
surge, no entanto, consagrado por transposição de directivas europeias ou por iniciativa autónoma do legislador nacional em múltiplas regulamentações técnico-sanitárias ${ }^{4}$.

Numa perspectiva jurídica, a doutrina tem entendido o princípio da precaução como decorrente de uma interpretação do princípio da prevenção, com uma ponderação agravada do interesse ambiental face a outros interesses, por força de uma leitura sistemática da Constituição e do imperativo da proporcionalidade (Canotilho, 1995; Gomes, 2013). Por seu lado, os estudos de interpretação económica do princípio da precaução separam os conceitos de prevenção e de precaução com base na possibilidade ou não de se associarem probabilidades de ocorrência objectivas, a partir de dados estatísticos, às consequências das atividades de risco, distinguindo assim entre riscos comprovados, aos quais se aplica a prevenção, e riscos não comprovados (incertos ou suspeitos), aos quais se aplica a precaução.

\section{Tendências recentes e perspectivas futuras}

De acordo com a investigação recente de alguns autores (Stokes, 2008; Peel, 2009; De Sadeleer, 2009; Noiville, 2015; Bocchi, 2016), depois de quase duas décadas de jurisprudência aplicada ao princípio da precaução, em particular no Tribunal Europeu de Justiça (TEJ) e na Organização Mundial do Comércio (OMC), é hoje possível identificar algumas tendências de homogeneização nas interpretações judiciais sobre a aplicação deste princípio, mesmo atendendo à diversidade de contextos e de sectores de regulação.

Invocado cautelosamente por muitos tribunais, dado o seu estatuto ainda incerto, tem conduzido a acções de precaução nalguns casos e surgido por vezes com o papel de justificação de legislação secundária (como directivas e regulamentos) mesmo não sendo mencionado explicitamente.

Os tribunais tendem a interpretar o princípio da precaução como um processo de decisão estruturado em diferentes passos metodológicos incluindo análises do risco e a avaliação das suas consequências com a ponderação dos interesses em presença (económicos, técnicos, políticos e sociais), devendo as medidas de precaução ser proporcionadas em relação aos riscos e aos seus efeitos. Além disso, as provas científicas sobre os perigos deverão ser sólidas e convincentes, tão completas quanto a informação disponível o permita, e não apenas meras

\footnotetext{
${ }^{4}$ Surge enunciado no artigo 3\%/1/f) da Lei n058/2005 de 29 de Dezembro (Lei da Água), que transpõe a Directiva n02000/60 de 23 de Outubro, no artigo 70/1 do Decreto Lei $n^{\circ} 173 / 2008$ de 26 de Agosto (Licenciamento ambiental), na Lei n027/2006 de 3 de Julho, artigo 5\%/c) (Lei de Bases da Protecção Civil) e no Decreto Lei no 142/2008 de 24 de Julho, artigo 4\%/e) (Regime Jurídico da Conservação da Natureza e da Biodiversidade) (Gomes, 2013 e Aragão, 2013).
}

DINÂMIA'CET - IUL, Centro de Estudos sobre a Mudança Socioeconómica e o Território

do Instituto Universitário de Lisboa (ISCTE-IUL)

Sala 2W4 - D | ISCTE-IUL - Av. das Forças Armadas

1649-026 Lisboa, PORTUGAL

Tel. (+351) 210464031 - Extensão 293101 | E-mail: dinamia@iscte-iul.pt | www.dinamiacet.iscte-iul.pt 


\section{Avaliação e gestão dos riscos não comprovados: \\ Estudo de casos da aplicação do princípio da precaução em Portugal}

hipóteses ou conjecturas de risco, de modo a evitar a aplicação indevida do princípio da precaução por razões puramente políticas ou proteccionistas (Noiville, 2015) ${ }^{5}$.

Se, por um lado, é desejável, em contextos sectoriais diversos e em quadros de incerteza, a preservação da flexibilidade na tomada de decisão, com avaliações do risco e com medidas de precaução numa base casuística, por outro lado, importará procurar ultrapassar pressões de grupos de interesses e interpretações dos tribunais, com diferentes exigências de provas, e resolver as atuais ambiguidades e possíveis arbitrariedades na implementação prática do princípio da precaução.

Com efeito, apesar dos progressos verificados e das propostas de alguns quadros metodológicos para a implementação prática do princípio da precaução, de âmbito setorial ou mais geral, em relatórios de entidades públicas ou em publicações científicas ${ }^{6}$, diversos autores consideram que faltam ainda instrumentos de enquadramento e também procedimentos mais particulares, a introduzir eventualmente na legislação, de modo a tornar mais efectivo o contributo do princípio da precaução na avaliação e na gestão dos riscos ambientais.

Assim, Sachs refere a necessidade de procedimentos para uma análise cuidada do risco, com regras para protecção da saúde pública, enquadradas em outras estratégias e medidas ambientais dos governos (Sachs, 2011) e Renn destaca a necessidade de definir critérios para apoio à avaliação dos riscos, como a magnitude dos impactos potenciais, a escala espacial e temporal ou a probabilidade de ocorrência (Renn, 2008).

Zander e Lofstedt destacam a grande relevância da análise económica para a ponderação de interesses e para a análise da proporcionalidade e da coerência das decisões ${ }^{7}$, devendo ser

\footnotetext{
${ }^{5}$ Estas provas não levantam totalmente as incertezas, pois nessa altura sair-se-ia do domínio da precaução, mas são consideradas obtidas a partir de documentação considerada suficiente sobre os perigos em causa. Por outro lado, a incerteza científica raramente surge (para o TEJ e a OMC) como demasiado elevada para impedir uma análise de risco e afectar a capacidade de realizar acções concretas, especialmente atendendo a que é sempre possível adoptar medidas provisórias e revisíveis (Noiville, 2015).

${ }^{6}$ Estes quadros metodológicos são, em alguns casos mais focalisados nos objetivos e orientações gerais, e noutros, mais operacionais, descrevendo o processo de análise e decisão como um conjunto de etapas sucessivas (CPP, 2010; IRGC, 2008; Bondi, 2011; EC, 2011; Klinke e Renn, 2012) sendo os seus elementos mais relevantes a análise da gravidade potencial dos impactos sobre o ambiente ou a saúde, os níveis de prova e o grau de precaução requerido, e a procura da proporcionalidade das medidas de precaução face à gravidade dos impactos. Outros quadros metodológicos, embora não expressamente referidos ao princípio da precaução, poderão contribuir para a implementação de medidas adequadas de gestão de riscos não comprovados. É o caso, no Reino Unido, da abordagem da tolerância ao risco ("tolerability of risk"), particularmente nos setores de saúde e segurança, que procura conciliar decisões baseadas em estimativas de confiança sobre riscos, com a garantia da consideração adequada das percepções do público (Bouder et al., 2007).

${ }^{7}$ Diversos modelos têm sido definidos para interpretação económica do princípio da precaução, como os modelos baseados na teoria da utilidade esperada, que analisam os efeitos da irreversibilidade dos danos ambientais e da flexibilidade das decisões em função da obtenção de informação futura, ou os modelos
} 
corrigidas insuficiências correntemente verificadas na valoração dos bens e dos danos ambientais (Zander, 2010; Lofstedt, 2014). Todavia, são importantes as implicações da incomensurabilidade de custos e benefícios (Aldred, 2012), muitas vezes não redutíveis a valores monetários num quadro de controvérsia e desconhecimento de informação ${ }^{8}$.

Tosun refere ainda a necessidade de explicitar e comunicar com mais clareza a fundamentação das decisões (Tosun, 2013), que deverão incluir as várias fontes de incerteza, a apresentação unilateral de provas, as áreas identificadas como de falta de conhecimento e informações sobre os métodos da análise utilizados. Formas de envolvimento e de participação pública que permitam a definição de níveis de risco aceitáveis socialmente e a legitimação social das medidas de precaução são igualmente importantes (Etienne, 2009; Oliveira et al., $2016)^{9}$.

Finalmente, vários autores sugerem a criação de uma entidade independente que possa apoiar reguladores e decisores políticos na implementação dos procedimentos de avaliação dos riscos e no acompanhamento da realização de medidas provisórias e proporcionadas de precaução, portanto revisáveis tendo em conta a evolução dos conhecimentos científicos (Godard, 2010; Lofstedt, 2014) ${ }^{10}$.

Uma definição mais precisa do princípio da precaução, num dado contexto social, cultural e político prevalecente, permitirá aliviar as dificuldades e as ambiguidades atuais dos tribunais nas aplicações da precaução e contribuir para uma solução mais satisfatória em termos de segurança jurídica.

multicritério, que consideram objetivos múltiplos (ambientais, económicos, sociais, etc.) na tomada de decisão e permitem a integração de processos participativos e deliberativos (Savage, 1954; Kahneman e Tversky, 1979; Gilboa e Scmeidler, 1989; Gollier e Treich, 2003; Stirling e Mayer, 2005; Gonçalves, 2013).

${ }^{8}$ Como afirma Cooney as controvérsias sobre o princípio da precaução são frequentemente disputas sobre como obter algum equilíbrio entre interesses concorrentes, num contexto de elevada incerteza ou grande falta de conhecimento em que não é possível uma solução técnica clara. A análise dos factores ecológicos, sócio - económicos e políticos, interagindo num sistema complexo com comportamento que não é possível prever ou quantificar, é por isso muitas vezes necessária (Cooney, 2005).

9 Jalava et al. (2016), referindo-se aos Estudos de Impacte Ambiental (na Finlândia), considera que as incertezas não têm sido analisadas com rigor e que, idealmente, os procedimentos de Avaliação de Impacte Ambiental deveriam ter em conta diferentes perspectivas de análise e permitir a comunicação entre os diferentes "stakeholders".

${ }^{10}$ Deve também ter-se em atenção que a racionalidade da escolha das medidas de precaução será sempre limitada pelo custo de obter informação sobre o futuro e pelo desconhecimento inevitável de alguns aspectos associados aos fenómenos incertos em análise. Lofstedt menciona ainda as dificuldades políticas que poderão resultar na prática, associadas a possíveis acusações a políticos por decisões passadas que tenham deixado de ser consideradas perigosas, ou a produtos não envolvendo perigo e que ficam fora do mercado pelo estigma de terem anteriormente sido considerados perigosos (Lofstedt, 2014). 


\section{QUADRO DE ANÁLISE}

Tendo por objetivo compreender as diferenças na interpretação da precaução na prática, pelas partes envolvidas e pelos tribunais, foi elaborado um quadro analítico tendo por base os atributos seguintes, que permitem caracterizar, no essencial, a aplicação do princípio da precaução (Stirling, 2017; Garnett \& Parssons, 2017; Sachs, 2011; CE, 2000; SEHN, 1998; UNCED, 1992):

- Natureza dos riscos

- Nível de exigência de prova

- Medidas aplicadas

Com este quadro de análise pretende-se realizar uma análise exploratória baseada em pressupostos simples para suprirem a ausência de informação sobre a natureza dos riscos e sobre critérios de proporcionalidade das decisões.

De acordo com este quadro as medidas a aplicar deverão ser mais severas e com níveis de exigência de prova menores para riscos mais graves.

Apresentam-se a seguir os critérios que serão considerados para a análise da natureza dos riscos, dos níveis de exigência de prova e dos níveis de severidade das medidas de precaução relativamente aos casos considerados neste estudo.

\subsection{Análise da natureza dos riscos}

Os riscos que devem ser objeto da aplicação do princípio da precaução traduzem, por definição, situações de incerteza quanto à informação e conhecimento sobre os perigos (são riscos não comprovados ou suspeitos) e de gravidade potencial dos efeitos da atividade ou da tecnologia em causa para o ambiente ou a saúde humana.

A incerteza sobre os riscos traduz a falta de compreensão dos factores explicativos das relações causa - efeito e o desconhecimento da probabilidade de ocorrência dos danos potenciais (Stirling, 2017, Aven, 2011)

Atendendo a que as acções de precaução poderão ser diferenciadas, com um nível de maior ou menor severidade em função da maior ou menor gravidade dos riscos, importa caracterizar o nível de gravidade associado a cada situação de risco.

Para a caracterização da gravidade potencial dos riscos consideram-se os seguintes critérios (Renn e Klinke, 2010; Bevan, 2009; Godard, 2005): 
- Relevância dos danos potenciais

- Dispersão geográfica

- Persistência no tempo

- Relevância dos interesses envolvidos

A relevância dos danos potenciais será considerada alta nos Casos em que estão em causa danos que ameaçam a saúde e a vida humana e moderada nos Casos em que estão em causa danos que ameaçam o mundo natural. Esta classificação tem por base estas duas dimensões consideradas por vários autores como as mais relevantes nos problemas ambientais (Harremoes et al., 2002; O' Connor e Spash, 2001; OCDE, 1997) ${ }^{11}$.

A dispersão geográfica dos riscos será considerada alta, moderada ou baixa nos diferentes casos consoante a área de influência respectiva.

A persistência dos riscos no tempo será considerada alta ou baixa em função da natureza irreversível ou não dos danos potenciais em causa.

Finalmente, os interesses envolvidos serão considerados pouco relevantes, relevantes ou muito relevantes consoante a importância atribuída na ponderação de interesses efectuada pelos tribunais.

Globalmente, o nível de gravidade potencial dos riscos será considerado alto quando todos os critérios tiverem o nível mais elevado e moderado quando a magnitude dos danos potenciais não for alta ou quando em mais de um dos critérios a avaliação não for do nível mais elevado (Quadro 1).

\footnotetext{
${ }^{11}$ Nesta classificação, a primeira dimensão pode ser associada aos riscos tecnológicos, e nela enquadramse problemas como a poluição em geral, a acumulação de resíduos tóxicos, o aquecimento global, e a segunda aos riscos de gestão dos recursos naturais, ao desaparecimento de habitats naturais e à perda de biodiversidade.
} 
Quadro 1 - Dimensões de risco e nível de gravidade potencial dos riscos

\begin{tabular}{|l|l|c|}
\hline \multicolumn{1}{|c|}{ Dimensão de risco } & \multicolumn{1}{|c|}{ Descrição } & Classificação \\
\hline Relevância dos danos & \multirow{2}{*}{$\begin{array}{l}\text { Danos para a saúde } \\
\text { potenciais }\end{array}$} & Danos para o mundo natural \\
\cline { 2 - 3 } \multirow{2}{*}{$\begin{array}{l}\text { Dispersão geográfica dos } \\
\text { riscos }\end{array}$} & Nacional & Moderada \\
\cline { 2 - 3 } & Regional & Alta \\
\cline { 2 - 3 } & Local & Moderada \\
\hline Persistência dos riscos & Irreversíveis & Alta \\
\cline { 2 - 3 } & Reversíveis & Baixa \\
\hline \multirow{2}{*}{ Relevância dos interesses } & Muito relevantes & Alta \\
\cline { 2 - 3 } & Relevantes & Moderada \\
\cline { 2 - 3 } & Pouco relevantes & Baixa \\
\hline
\end{tabular}

\begin{tabular}{|l|c|}
\hline \multicolumn{1}{|c|}{ Descrição } & Nível de gravidade \\
\hline Todas as dimensões de risco com o nível mais elevado & Alto \\
\hline $\begin{array}{l}\text { A relevância dos danos potenciais não é alta ou pelo } \\
\text { menos uma das dimensões de risco não é alta }\end{array}$ & Moderado \\
\hline
\end{tabular}

\subsection{Análise do nível de exigência de prova}

Face às incertezas existentes, o nível de robustez das provas científicas relativas à existência ou não de riscos graves constitui a base necessária para definir o grau de preocupação quanto aos perigos e, assim, para decidir ou não aplicar o princípio da precaução e selecionar as medidas a propor.

Na tomada de decisão, os requisitos de prova, que deverão considerar os riscos potenciais da atividade em causa e também a ponderação de todos os custos e benefícios envolvidos, poderão traduzir desde uma simples suspeição de risco até a uma forte presunção de risco justificada teórica e empiricamente.

Considera-se, assim, a seguinte caracterização dos níveis de prova (Quadro 2):

- Nível de exigência baixo: Quando o tribunal assume a dúvida sobre os perigos, apesar da falta de provas científicas mais seguras, que entende não serem possíveis neste momento. Este nível é menos exigente quanto aos níveis de prova, devendo o ónus da prova ficar para a entidade responsável pela atividade e não para os seus beneficiários. 
- Nível de exigência moderado: Quando o tribunal, apesar das incertezas, se satisfaz com o cumprimento de margens de segurança (limiares legais de risco) ${ }^{12}$ ou de estratégias adaptativas como medidas de minimização de impactes negativos

- Nível de exigência alto: Quando o tribunal requer a reunião de provas muito seguras e cientificamente atualizadas sobre os perigos e a análise compreensiva dos riscos. Poderá estar incluida alguma orientação sobre a margem de segurança requerida. A ponderação de benefícios e de custos, económicos, sociais ou outros é igualmente considerada relevante.

Os três níveis de exigência de prova correspondem a situações intoleráveis, toleráveis ou aceitáveis de risco na perspectiva do decisor e deverão traduzir os níveis de percepção e aceitabilidade social dos riscos. Para que se decida aplicar a precaução deverá ser exigida uma crescente quantidade e qualidade de provas de perigo das situações consideradas intoleráveis para as situações consideradas aceitáveis.

Quadro 2 - Nível de exigência de prova

\begin{tabular}{|l|c|}
\hline \multicolumn{1}{|c|}{ Descrição } & Nível de exigência de prova \\
\hline $\begin{array}{l}\text { O tribunal assume a dúvida sobre os perigos, na } \\
\text { impossibilidade de se dispor de provas científicas mais seguras }\end{array}$ & Baixo \\
\hline $\begin{array}{l}\text { O tribunal requer o cumprimento de limiares legais ou de } \\
\text { medidas de minimização de impactes negativos como prova da } \\
\text { não existência de perigo }\end{array}$ & Moderado \\
\hline $\begin{array}{l}\text { O tribunal requer provas muito seguras e cientificamente } \\
\text { atualizadas sobre os perigos e a análise compreensiva dos } \\
\text { riscos. A ponderação de benefícios e de custos, económicos, } \\
\text { sociais ou outros, é igualmente considerada relevante }\end{array}$ & Alto \\
\hline
\end{tabular}

\footnotetext{
${ }^{12}$ Não se consideram as margens de segurança no nível de exigência baixo uma vez que, como alguns autores (Wiener e Rogers, 2002), se admitir não estarem esclarecidos os custos económicos e sociais que poderão estar a elas associados e ainda ao facto de poder permanecer incerteza quanto aos efeitos de exposições prolongadas no tempo mesmo aos níveis de segurança pré-fixados.
} 


\subsection{Análise da severidade das medidas de precaução}

Tendo em atenção a diversidade das medidas e dos resultados possíveis requeridos para a decisão de precaução e as diferentes formulações e interpretações do princípio da precaução, consideram-se, de acordo com o que propõem alguns autores (Sachs, 2011; Zander, 2010; Lofstedt; 2014, Garnett e Parsons, 2017), dois níveis de aplicação possível deste princípio, que se traduzirão em diferentes tipos de medidas a propor (Quadro 3):

- aplicação "fraca” do princípio da precaução

- aplicação "forte" do princípio da precaução

No primeiro nível considera-se um espectro vasto de possíveis medidas de precaução, incluindo ações menos restritivas como medidas de minimização ou de compensação de impactes negativos ou medidas de simples observação e vigilância ou de apoio ao desenvolvimento do conhecimento científico sobre os riscos.

No segundo nível consideram-se ações mais restritivas como a proibição/suspensão de actividades com risco até um melhor esclarecimento das incertezas existentes ${ }^{13}$.

Os dois níveis de precaução correspondem, assim, a opções de redução ou de evitação dos riscos. O primeiro deve aplicar-se a situações avaliadas como de riscos considerados toleráveis e o segundo a situações de risco a que estão associadas consequências consideradas demasiado severas. A riscos considerados aceitáveis não será necessário aplicar medidas de precaução.

Consequentemente, e de acordo com os níveis de exigência de prova acima definidos, a aplicação do princípio da precaução "fraca" deverá estar associada ao nível de exigência de prova de perigo moderado, enquanto a aplicação "forte" deverá estar associada ao nível de exigência de prova baixo. Às situações em que o princípio da precaução não é aplicado deverá estar associado o nível de exigência de prova alto. Esta correspondência entre níveis de severidade das medidas de precaução e níveis de exigência de prova traduz, aliás, a tendência constatada a partir da análise de múltiplos casos de aplicação do princípio da precaução (Garnett e Parsons, 2017).

13 Neste termos, a Declaração de Wingspread representa uma abordagem mais "forte" à precaução do que a Declaração do Rio e a Comunicação da Comissão Europeia.

DINÂMIA'CET - IUL, Centro de Estudos sobre a Mudança Socioeconómica e o Território

do Instituto Universitário de Lisboa (ISCTE-IUL)

Sala 2W4 - D | ISCTE-IUL - Av. das Forças Armadas

1649-026 Lisboa, PORTUGAL

Tel. (+351) 210464031 - Extensão 293101 | E-mail: dinamia@iscte-iul.pt | www.dinamiacet.iscte-iul.pt 
Quadro 3 - Nível de severidade das medidas de precaução

\begin{tabular}{|l|c|}
\hline \multicolumn{1}{|c|}{ Descrição } & Nível de precaução \\
\hline $\begin{array}{l}\text { Ações mais restritivas como a proibição/suspensão de actividades com } \\
\text { risco até um melhor esclarecimento das incertezas existentes }\end{array}$ & Forte \\
\hline $\begin{array}{l}\text { Espectro vasto de possíveis medidas de precaução incluindo ações menos } \\
\text { restritivas, como medidas de minimização ou compensação de impactes } \\
\text { negativos, de monitorização e vigilância. }\end{array}$ & Fraco \\
\hline
\end{tabular}

\subsection{Análise da proporcionalidade das medidas de precaução}

Finalmente, o quadro de análise inclui uma análise da proporcionalidade das medidas de precaução em relação à gravidade dos riscos. Trata-se de um importante critério de boa governação na avaliação das opções tomadas para gestão dos riscos.

As medidas de precaução serão consideradas proporcionais à gravidade dos riscos se forem mais severas para danos potenciais mais graves. Assim (Quadro 4):

- As acções de precaução mais restritivas, associadas ao nível de precaução "forte" (e a níveis de exigência de prova baixos) serão proporcionais nos casos em que a gravidade dos riscos é maior (gravidade alta)

- As acções menos restrictivas, associadas ao nível de precaução "fraco" (e a níveis de exigência de prova moderados) serão proporcionais aos casos em que a gravidade dos riscos é menor (gravidade moderada).

- Nas outras situações não haverá proporcionalidade das medidas de precaução em relação à gravidade dos riscos.

Quadro 4 - Análise da proporcionalidade das medidas de precaução

\begin{tabular}{|l|l|c|}
\hline \multicolumn{1}{|c|}{ Gravidade dos riscos } & \multicolumn{1}{|c|}{ Nível de precaução } & Análise de proporcionalidade \\
\hline Gravidade alta & Precaução forte & \multirow{2}{*}{ Proporcionalidade } \\
\hline Gravidade moderada & Precaução fraca & \multirow{2}{*}{ Não proporcionalidade } \\
\hline Gravidade alta & Precaução fraca & \\
\hline Gravidade moderada & Precaução forte & \\
\hline
\end{tabular}

Finalmente, a figura seguinte sintetiza o quadro de análise, o qual representa a integração da análise, da avaliação e da gestão dos riscos não comprovados. 


\section{Figura 1 - Síntese do quadro de análise}

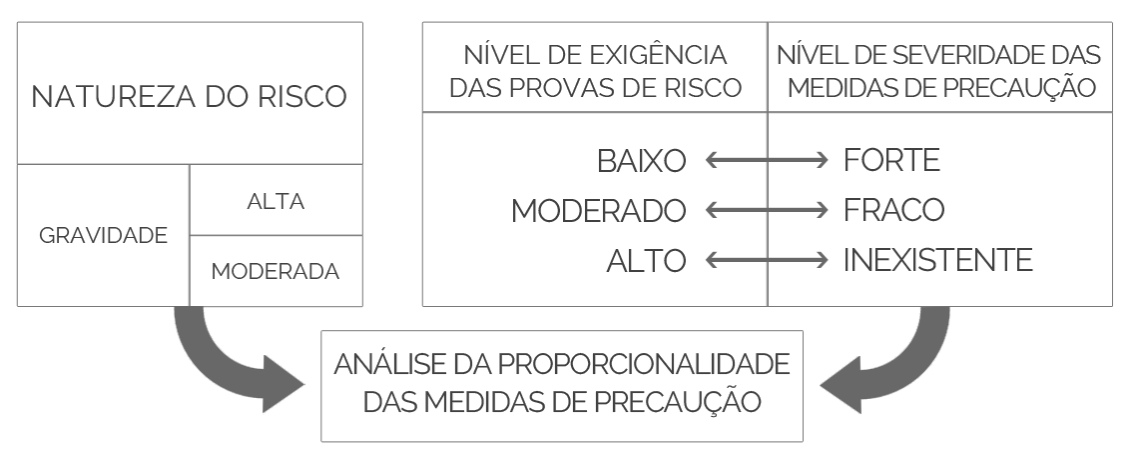

\section{ANÁLISE DE CASOS}

A partir de uma pesquisa no site da Base de dados Jurídico-Documentais da Direcção - Geral dos Serviços Informáticos do Ministério da Justiça sobre a aplicação do princípio da precaução, foi possível identificar um conjunto de processos e os respectivos acórdãos do Supremo Tribunal Administrativo (STA) e dos Tribunais Centrais Administrativos do Norte (TCAN) e do Sul (TCAS) relativos a procedimentos cautelares na área do ambiente em que o princípio da precaução é invocado, nas alegações das partes envolvidas ou dos tribunais.

Com base no conjunto de acórdãos identificado foi selecionado um conjunto de processos (aqui designados por casos) desde 2007, para os quais se procurou conhecer todo o percurso verificado desde as sentenças dos Tribunais Administrativos e Fiscais (TAFs) em $1^{a}$ instância, passando pelos acórdãos dos Tribunais Centrais Administrativos (TCAs) e do Supremo Tribunal Administrativo (STA). Para obter algumas destas sentenças e acórdãos, que não estão disponíveis eletronicamente, foi necessário contactar diretamente o TCAN, o TCAS e alguns TAFs.

Estes processos situam-se nos áreas de actividade seguintes: co-incineração de resíduos, linhas de transporte de energia de alta tensão, construção de barragem, recursos de pesca e parque eólico.

Trata-se de áreas que envolvem riscos de danos, para a saúde pública ou para o ambiente, em relação aos quais não existe conhecimento suficiente quanto à sua magnitude e probabilidade de ocorrência, isto é, trata-se de riscos não comprovados. São ainda riscos involuntários, difíceis ou impossíveis de evitar mesmo com comportamento vigilante das pessoas ou entidades que estão sujeitas ao risco. 


\subsection{Apresentação dos Casos}

Os casos que foram selecionados para análise são apresentados sumariamente no Quadro 5, com indicação das suas áreas de actividade, ano da decisão no STA e breve descrição (os números dos processos respectivos são indicados nas referências bibliográficas).

Quadro 5 - Casos por área de atividade e ano de decisão final e sua descrição breve

\begin{tabular}{|c|c|c|c|}
\hline Área de atividade & Casos & Ano & Descrição breve \\
\hline \multirow{4}{*}{ Co-incineração } & 1 & 2007 & $\begin{array}{l}\text { Suspensão da eficácia do Despacho do Ministério do Ambiente que } \\
\text { permitiu o licenciamento da co-incineração em Souselas sem a } \\
\text { realização de Avaliação de Impacte Ambiental. }\end{array}$ \\
\hline & 2 & 2009 & $\begin{array}{l}\text { Suspensão da eficácia dos actos de concessão das licenças ambiental, } \\
\text { de instalação e de exploração para a co-incineração em Souselas. }\end{array}$ \\
\hline & 3 & 2008 & $\begin{array}{l}\text { Suspensão da eficácia do Despacho do Ministério do Ambiente que } \\
\text { dispensou de Avaliação de Impacte Ambiental a co-incineração na } \\
\text { fábrica do Outão. }\end{array}$ \\
\hline & 4 & 2010 & $\begin{array}{l}\text { Suspensão da eficácia dos actos de concessão das licenças ambiental, } \\
\text { de instalação e de exploração para a co-incineração na fábrica do } \\
\text { Outão. }\end{array}$ \\
\hline \multirow{2}{*}{$\begin{array}{l}\text { Linha de alta } \\
\text { tensão }\end{array}$} & 5 & 2014 & $\begin{array}{l}\text { Pedido de nulidade do acto de licenciamento do projeto de linha de alta } \\
\text { tensão Fanhões - Trajouce (Sintra) }\end{array}$ \\
\hline & 6 & 2010 & $\begin{array}{l}\text { Suspensão da eficácia do acto de licenciamento do projeto de Linha de } \\
\text { alta tensão Ribabelide - Valdigem (Lamego) }\end{array}$ \\
\hline \multirow[b]{2}{*}{ Barragem } & 7 & 2010 & $\begin{array}{l}\text { Suspensão da eficácia da construção da barragem do Sabor pela não } \\
\text { prorrogação da validade da Declaração de Impacte Ambiental e pela } \\
\text { não realização das medidas de minimização dos impactes negativos. }\end{array}$ \\
\hline & 8 & 2009 & $\begin{array}{l}\text { Suspensão do contrato de concessão da utilização de recursos hídricos } \\
\text { para captação de águas superficiais para a produção de energia } \\
\text { hidroeléctrica na barragem do Sabor. }\end{array}$ \\
\hline $\begin{array}{l}\text { Recursos de } \\
\text { Pesca }\end{array}$ & 9 & 2014 & $\begin{array}{l}\text { Pedido de condenação do Estado a pagar indemnização aos pescadores } \\
\text { dos Açores pela omissão de fiscalização de subárea da Zona } \\
\text { Económica Exclusiva nos Açores. }\end{array}$ \\
\hline Parque Eólico & 10 & 2011 & $\begin{array}{l}\text { Suspensão da eficácia de Despacho do Min. Ambiente de prorrogação } \\
\text { da Declaração de Impacte Ambiental do Parque Eólico de Alvaiáze e } \\
\text { da aprovação do projeto de execução do Parque. }\end{array}$ \\
\hline
\end{tabular}


$\mathrm{Na}$ área da co - incineração de resíduos perigosos consideram-se quatro casos, relativos a acções dos Municípios de Coimbra ( 2 casos) e de Sesimbra, Palmela e Setúbal (2 casos) contra os Ministérios do Ambiente e da Economia e as empresas Cimpor e Secil. Estas acções são relativas aos possíveis efeitos para a saúde pública e o ambiente da atividade das fábricas de Souselas e do Outão. Estão em causa a suspensão da eficácia do Despacho do Ministério do Ambiente que dispensou as fábricas de Souselas e do Outão de Avaliação de Impacte Ambiental (AIA) e da atribuição das licenças ambiental, de instalação e de exploração nessas fábricas.

$\mathrm{Na}$ área das linhas de transporte de energia de alta tensão os dois casos considerados resultam de acções de uma freguesia do concelho de Sintra (1 caso) e de um casal de proprietários (1 caso) contra o Ministério da Economia e empresas de produção de energia eléctrica relativamente aos riscos da exposição aos efeitos electromagnéticos associados àquelas linhas.

$\mathrm{Na}$ área da construção de barragens, consideram-se dois casos que resultam de acções da Quercus, Liga de Protecção da Natureza e outras organizações contra a empresa de electricidade EDP num dos casos e contra o Instituto da Água no outro. Têm que ver com os possíveis efeitos negativos para o ambiente da construção da barragem do Sabor.

Um outro caso, relativo à utilização de recursos da pesca, resulta de uma acção de uma associação de pescadores contra o Ministério da Defesa devida à falta de controlo sobre o risco de esgotamento desses recursos.

Um último caso refere-se ao parque eólico de Alvaiázere e resulta de uma acção da Quercus contra o Ministério do Ambiente e uma sociedade eléctrica devida aos possíveis efeitos negativos que poderão resultar para certas espécies de fauna.

\subsection{Posição das entidades envolvidas}

\section{(i) Posição das entidades que defendem a aceitação das providências cautelares}

Para fundamentar a aceitação de uma providência cautelar, de acordo com o Código de Processo nos Tribunais Administrativos (CPTA), é necessário verificar-se a existência de perigo de danos com carácter irreversível ou de difícil reparação e uma ponderação de interesses favorável à aceitação dessa providência face à sua recusa (CPTA (2002) artigo $120^{\circ}, \mathrm{n}^{\circ} 1 \mathrm{e} 2$ ).

Quanto à existência de perigo, as entidades que defendem a aceitação de providências cautelares em defesa do que consideram serem os interesses do ambiente ou da saúde pública referem, nos diferentes casos estudados, que, por falta de conhecimento, não é possível garantir 


\section{Avaliação e gestão dos riscos não comprovados: \\ Estudo de casos da aplicação do princípio da precaução em Portugal}

a não existência de danos potenciais, ou que os factos apresentados nas acções ou nos recursos são demonstrativos da existência de riscos de ocorrência de danos irreversíveis ou de difícil reparação que importa evitar. Estes riscos são devidos aos efeitos dos poluentes orgânicos persistentes que se libertam nas operações de co-incineração, à exposição a radiações das linhas de energia de alta tensão ou à perda de valores ambientais e paisagísticos ou de recursos naturais.

Quanto à ponderação de interesses, a aceitação das providências cautelares surge sempre como mais favorável do que a sua recusa no balanço entre benefícios e custos para os interesses envolvidos. Assim, por exemplo, a salvaguarda dos direitos dos cidadãos à saúde e ao ambiente é considerada mais relevante do que a redução do custo do combustível, nos casos da coincineração de resíduos, ou do que a afectação dos interesses energéticos, no caso das linhas de alta tensão. No caso da construção da barragem do Sabor, os valores ambientais e paisagísticos deverão prevalecer sobre a produção de energia hidroeléctrica.

Considera-se ainda existirem processos alternativos disponíveis para tratamento térmico de resíduos e também alternativas de traçado de linhas de energia eléctrica e de produção hidroeléctrica.

As fontes de informação dos argumentos apresentados são os estudos e pareceres médicos ou estudos técnicos e económicos mencionados que apoiam as posições defendidas. Outros estudos ou pareceres com conclusões divergentes foram considerados insuficientes ou menos relevantes.

Pode constatar-se ainda que, quer os limiares de risco definidos, relativos às emissões poluentes da co - incineração de resíduos e às ondas electromagnéticas das linhas de energia de alta tensão, quer as medidas de minimização de impactes ambientais negativos, nos casos da barragem do Baixo Sabor e do Parque eólico de Alvaiázere não foram considerados suficientes para evitarem os danos potenciais para a saúde humana ou para espécies, habitats ou ecossistemas relevantes.

O princípio da precaução é aplicado explicitamente como base de justificação para a aceitação das providências cautelares nos casos em que se considera existir falta de conhecimento e se admitir a existência de danos potenciais (Casos 1, 3, 5, 7). Noutros (Casos 2 e 4) é mencionada a sua relevância mas não é aplicado por se admitir já provada a existência de perigo. 
Pode ainda considerar-se invocado implicitamente nos restantes Casos (6, 8, 9 e 10), pela referência que é feita à falta de conhecimento de prova ou de inversão do ónus da prova dos danos para a entidade promotora da atividade de risco.

\section{(ii) Posição das entidades que estão contra a aceitação das providências cautelares}

As entidades promotoras das atividades económicas consideram, pelo contrário, com base nos pareceres científicos e técnicos e nos resultados dos testes referidos, demonstrada a inexistência de perigo de danos potenciais com carácter irreversível ou não demonstrada a sua existência. Os riscos invocados são considerados apenas como meras conjecturas sem provas concretas e objectivas. Nos casos relativos às linhas de energia de alta tensão é salientado ainda o cumprimento dos limiares legais de risco e a implementação de medidas de minimização de impactes negativos na sequência da realização dos estudos de impacte ambiental.

A posição destas entidades no que diz respeito à ponderação de interesses é também desfavorável às providências cautelares, invocando que os danos que resultariam da recusa das providências cautelares são inferiores aos que resultariam da sua aceitação. Nos casos relativos à co-incineração, os interesses públicos da eliminação do passivo ambiental de resíduos industriais perigosos e da sua não deposição em aterro são considerados muito relevantes e prioritários. Nos casos relativos às linhas de alta tensão, a necessidade pública do reforço da rede de energia, e no caso da barragem do Sabor, os interesses da produção de energia hidroeléctrica, são igualmente considerados prioritários.

Assim, a perspectiva das entidades promotoras das atividades económicas quanto à aplicação do princípio da precaução aos casos em análise é necessariamente diferente da perspectiva das entidades que defendem a aceitação das providências cautelares.

Se, nalguns casos, a validade jurídica do princípio da precaução é reconhecida embora não a sua aplicabilidade por se considerar provada a inexistência de danos ambientais (Casos $3 \mathrm{e}$ 4), noutros casos (Casos 1 e 2), a validade jurídica do princípio da precaução é colocada em causa "por falta de consagração na ordem jurídica portuguesa".

No entanto, no Caso 2 refere-se também não ter sido apurado se os dados científicos recentes justificavam ou não o recurso ao princípio da precaução e, no Caso 3, afirma-se que a não aplicabilidade deste princípio resulta do facto de não estar em causa matéria com incerteza "nomeadamente por falta de provas científicas". Constata-se, assim, nestes dois casos, alguma ambiguidade na interpretação do próprio conceito de precaução, o qual deve ser aplicado em situações de incerteza face à insuficiência das provas e à dúvida sobre os riscos. 


\subsection{Fundamentação das decisões dos Tribunais}

Em todos os dez casos verificaram-se recursos para os tribunais de $2^{\mathrm{a}}$ instância e em 9 casos para o STA. Nos Quadros 6 e 7 identificam-se os tribunais por onde transitaram os processos e as decisões respectivas em relação à aceitação ou não das providências cautelares.

Em primeira instância (TAFs), os tribunais foram favoráveis às providências cautelares em apenas 3 dos 10 casos analisados, sendo 2 relativos à co-incineração de resíduos e o outro relativo à fiscalização dos recursos de pesca nos Açores.

Na segunda instância (TCAS e TCAN), os tribunais foram favoráveis às providências cautelares em 5 casos: nos casos em que a sentença na $1^{\text {a }}$ instância já fora favorável e também em mais dois casos em que a sentença anterior fora desfavorável, um relativo à co-incineração e o outro relativo a uma linha de energia de alta tensão.

Finalmente, na terceira e última instância, o Supremo Tribunal Administrativo foi sempre desfavorável às providências cautelares.

Quadro 6 - Decisões favoráveis (+) ou desfavoráveis (-) às providências cautelares por área de atividade, caso e Tribunal

\begin{tabular}{|c|c|c|c|c|c|c|c|c|c|c|c|c|}
\hline \multirow{2}{*}{$\begin{array}{ll}\text { Área } & \text { de } \\
\text { actividade }\end{array}$} & \multirow[t]{2}{*}{ Caso } & \multicolumn{8}{|c|}{ TAF } & \multirow[t]{2}{*}{ TCAS } & \multirow[t]{2}{*}{ TCAN } & \multirow[t]{2}{*}{ STA } \\
\hline & & Coimbra & Almada & Sintra & Viseu & Lisboa & Mirandela & P. Delgada & Leiria & & & \\
\hline Co-incineração & $\begin{array}{l}1 \\
2 \\
3 \\
4\end{array}$ & $\begin{array}{l}+ \\
-\end{array}$ & $\begin{array}{l}+ \\
-\end{array}$ & & & & & & & $\begin{array}{l}+ \\
-\end{array}$ & $\begin{array}{l}+ \\
+\end{array}$ & $\begin{array}{l}- \\
- \\
- \\
-\end{array}$ \\
\hline $\begin{array}{c}\text { Linha de alta } \\
\text { tensão }\end{array}$ & $\begin{array}{l}5 \\
6 \\
\end{array}$ & & & - & - & & & & & - & + & $\begin{array}{l} \\
-\end{array}$ \\
\hline Barragem & $\begin{array}{l}7 \\
8\end{array}$ & & & & & - & - & & & - & - & - \\
\hline Recursos de pesca & 9 & & & & & & & + & & + & & - \\
\hline Parque Eólico & 10 & & & & & & & & - & - & & \\
\hline
\end{tabular}


Quadro 7 - Número de decisões favoráveis ou desfavoráveis às providências cautelares por instância e área de atividade

\begin{tabular}{|c|c|c|c|c|}
\hline Casos & Área de atividade & $\mathrm{N}^{\circ}$ total de casos & $\begin{array}{c}\mathrm{N}^{\circ} \text { de decisões } \\
\text { favoráveis }\end{array}$ & $\begin{array}{l}\mathrm{N}^{\circ} \text { de decisões } \\
\text { desfavoráveis }\end{array}$ \\
\hline \multirow[t]{2}{*}{$\underline{1^{a} \text { instância }}$} & Co-incineração & 4 & 2 & 2 \\
\hline & Linha de alta tensão & 2 & & 2 \\
\hline \multirow[t]{4}{*}{ (TAFs) } & Barragem & 2 & & 2 \\
\hline & Recursos de pesca & 1 & 1 & \\
\hline & Parque eólico & 1 & & 1 \\
\hline & Total & 10 & 3 & 7 \\
\hline \multirow[t]{2}{*}{$\underline{2^{\mathrm{a}} \text { instância }}$} & Co-incineração & 4 & 3 & 1 \\
\hline & Linha de alta tensão & 2 & 1 & 1 \\
\hline \multirow[t]{4}{*}{ (TCAS/TCAN) } & Barragem & 2 & & 2 \\
\hline & Recursos de pesca & 1 & 1 & \\
\hline & Parque eólico & 1 & & 1 \\
\hline & Total & 10 & 5 & 5 \\
\hline \multirow[t]{2}{*}{$\underline{3^{\mathrm{a}} \text { instância }}$} & Co-incineração & 4 & & 4 \\
\hline & Linha de alta tensão & 2 & & 2 \\
\hline \multirow[t]{3}{*}{ (STA) } & Barragem & 2 & & 2 \\
\hline & Recursos de pesca & 1 & & 1 \\
\hline & Total & 9 & & 9 \\
\hline
\end{tabular}

Nas secções seguintes apresenta-se brevemente uma análise da fundamentação das decisões dos tribunais nas várias instâncias de decisão relativamente aos casos estudados. Nos quadros $8,9 \mathrm{e}$ 10 incluem-se elementos seleccionados como mais relevantes relativos aos níveis de exigência de prova de perigo ou ao sentido das decisões dos tribunais.

\section{$\underline{1^{\mathrm{a}} \text { instância }}$}

Na $1^{\text {a }}$ instância, verificam-se três decisões favoráveis às providências cautelares (Casos 1, 3 e 9) e sete posições desfavoráveis (nos outros casos).

As decisões dos TAFs que são favoráveis às providências cautelares baseiam-se na aplicação do princípio da precaução nos Casos 1 e 3, relativos à co-incineração de resíduos, como forma de lidarem com a incerteza resultante da falta de conhecimento sobre os danos potenciais, requerendo a suspensão da co-incineração com vista ao prosseguimento dos estudos de avaliação ambiental. No Caso 3 a aplicabilidade do princípio da precaução "basta-se com a existência de meras possibilidades de dano ambiental" e o ónus da prova é invertido para o promotor da actividade de co-incineração. No Caso 9, o princípio da precaução não é referido

DINÂMIA'CET - IUL, Centro de Estudos sobre a Mudança Socioeconómica e o Território

do Instituto Universitário de Lisboa (ISCTE-IUL)

Sala 2W4 - D | ISCTE-IUL - Av. das Forças Armadas

1649-026 Lisboa, PORTUGAL

Tel. (+351) 210464031 - Extensão 293101 | E-mail: dinamia@iscte-iul.pt | www.dinamiacet.iscte-iul.pt 
explicitamente, mas parece estar implícito na fundamentação da decisão com base na constatação de danos potenciais irreversíveis para os ecossistemas e para a economia.

\section{Quadro 8 - Elementos de fundamentação das decisões na $1^{a}$ instância}

\begin{tabular}{|c|c|c|c|}
\hline & \multicolumn{2}{|r|}{ Caso } & \multirow[t]{2}{*}{ Elementos de fundamentação da decisão } \\
\hline & $\mathrm{N}^{\mathrm{o}}$ & Descrição & \\
\hline \multirow{3}{*}{ 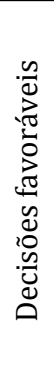 } & 1 & $\begin{array}{l}\text { Coincineração em Souselas } \\
\text { (Dispensa de AIA) (2007) }\end{array}$ & $\begin{array}{l}\text { Os factos conhecidos não traduzem falta de fundamento de perigo. } \\
\text { Falta conhecimento sobre algumas condições técnicas de } \\
\text { funcionamento e eventuais efeitos para a saúde das populações. }\end{array}$ \\
\hline & 3 & $\begin{array}{l}\text { Coincineração no Outão } \\
\text { (Dispensa de AIA) (2008) }\end{array}$ & $\begin{array}{l}\text { Os factos não indiciam uma manifesta falta de fundamento de } \\
\text { perigo para o ambiente e para a saúde pública. }\end{array}$ \\
\hline & 9 & $\begin{array}{lll}\text { Recursos de } & \text { pesca } \\
\text { (Fiscalização) } & (2013)\end{array}$ & $\begin{array}{l}\text { Com a diminuição da fiscalização na região, aumentam os danos } \\
\text { irreversíveis potenciais para os ecossistemas e para a economia. }\end{array}$ \\
\hline \multirow{7}{*}{ 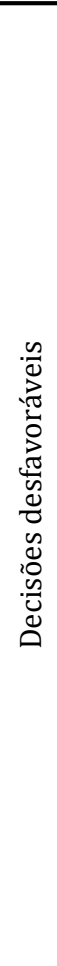 } & 2 & $\begin{array}{l}\text { Coincineração em Souselas } \\
\text { (licenças) (2009) }\end{array}$ & $\begin{array}{l}\text { Apenas foram feitas alegações de danos hipotéticos. Não se pode } \\
\text { concluir haver danos superiores aos legalmente permitidos. }\end{array}$ \\
\hline & 4 & $\begin{array}{l}\text { Coincineração no Outão } \\
\text { (licenças) (2010) }\end{array}$ & $\begin{array}{l}\text { Foi emitida DIA favorável, foram cumpridos os limites legais para } \\
\text { as emissões e existem meios de monitorização fiáveis }\end{array}$ \\
\hline & 5 & $\begin{array}{l}\text { Projeto de linha de alta } \\
\text { tensão (Sintra) (2014) }\end{array}$ & $\begin{array}{l}\text { As populações da área da freguesia não são afectadas. De qualquer } \\
\text { modo, o projecto obteve uma Declaração de Impacte Ambiental } \\
\text { favorável e os limiares legais de risco foram cumpridos. }\end{array}$ \\
\hline & 6 & $\begin{array}{l}\text { Projeto de linha de alta } \\
\text { tensão (Lamego) (2010) }\end{array}$ & $\begin{array}{l}\text { Apenas foram aventadas conjecturas sobre os perigos. Foi } \\
\text { utilizado como base de prova desfavorável ao projecto um estudo } \\
\text { descontextualizado e não relevante cientificamente. }\end{array}$ \\
\hline & 7 & $\begin{array}{ll}\text { Barragem } & \text { do } \quad \text { Sabor } \\
\text { (Medidas de } & \text { minimização) } \\
(2010) & \end{array}$ & $\begin{array}{l}\text { As medidas de minimização e compensação permitem evitar } \\
\text { danos irreparáveis sobre espécies e habitats. A barragem é muito } \\
\text { relevante para a produção de energia. }\end{array}$ \\
\hline & 8 & $\begin{array}{lrr}\text { Barragem } & \text { do } & \text { Sabor } \\
\text { (Utilização } & \text { de } & \text { recursos } \\
\text { hídricos) (2009) } & \\
\end{array}$ & $\begin{array}{l}\text { Os factos alegados não permitem dar como provada a existência } \\
\text { de perigos. }\end{array}$ \\
\hline & 10 & Parque eólico (2011) & $\begin{array}{l}\text { Medidas de minimização dos impactes negativos são adequadas } \\
\text { para atenuar os riscos de destruição dos habitats naturais e não } \\
\text { prejudicam os interesses económicos envolvidos. }\end{array}$ \\
\hline
\end{tabular}

Fonte: Sentenças dos Tribunais Fiscais e Administrativos (ver nas referências bibliográficas)

Nos restantes casos, os tribunais de $1^{\mathrm{a}}$ instância consideram cumpridos os limiares legais de risco ou adequadas as medidas de minimização de impactes negativos (Casos 2, 4, 5, 7 e 10) ou existirem apenas conjecturas ou insuficiência de factos sobre os perigos (Casos 6 e 8). O princípio da precaução é mencionado apenas no Caso 5, considerado implícito na aplicação das medidas de minimização destinadas a "acautelar os riscos mais gravosos". 


\section{Avaliação e gestão dos riscos não comprovados: \\ Estudo de casos da aplicação do princípio da precaução em Portugal}

De referir que as posições dos tribunais nos Casos 2 e 4 contrariam as posições tomadas pelos mesmos tribunais, dois anos antes, relativamente às mesmas unidades fabris (fábricas de Souselas e do Outão) nos Casos 1 e 3 respectivamente. Naqueles Casos, os TAFs são desfavoráveis às providências cautelares, mas não deixou entretanto de haver incerteza quanto aos potenciais danos da co - incineração. No Caso 4 o TAF reconhece, aliás, que se desconhece o tempo de exposição a partir do qual poderão verificar-se danos para a saúde humana.

\section{$\underline{2^{\mathrm{a}} \text { instância }}$}

$\mathrm{Na} 2^{\mathrm{a}}$ instância, são cinco as decisões favoráveis às providências cautelares (Casos 1, 2, 3, 6 e 9) e cinco as decisões desfavoráveis (Casos 4, 5, 7, 8 e 10) (Quadro 9). Dois dos casos com decisão agora favorável à providência cautelar tiveram decisão desfavorável na $1^{\mathrm{a}}$ instância (Casos 2 e 6).

O princípio da precaução é invocado pelos tribunais em todos os casos em que a decisão é favorável à providência cautelar.

Os tribunais valorizam a dúvida existente quanto aos perigos para a saúde pública e para o ambiente, quer da co-incineração de resíduos quer da linha de energia de alta tensão, recomendando estudos de aprofundamento do conhecimento sobre os perigos (Casos 1, 2, 3 e 6) e consideram provados os danos ecológicos potenciais para os recursos da pesca (Caso 9). Neste último Caso, embora não seja invocado o princípio da prevenção, a decisão é justificada com a necessidade de agir com antecipação para proteger o ambiente face à suspeita de danos potenciais graves cuja demonstração não é possível, pelo que se trata efetivamente de uma decisão de precaução.

Constata-se que, contrariamente ao que sucede nos casos em que está em causa a dispensa da realização de Avaliação de Impacte Ambiental (AIA) na fábrica de Souselas e na do Outão (Casos 1 e 3), em que quer o TCAN quer o TCAS confirmam as decisões da instância anterior, favoráveis às providências cautelares, já nos casos em que é requerida a suspensão das licenças concedidas àquelas fábricas (Casos 2 e 4), enquanto o TCAS mantém a decisão da instância anterior, desfavorável à providência cautelar, o TCAN, perante recurso similar, altera o sentido da decisão da instância anterior (passa a favorável), valorizando agora a dúvida sobre os riscos. Também em relação aos projetos de linhas de alta tensão, perante riscos de natureza idêntica, o sentido das decisões é diferente para o TCAS (Caso 5) e o TCAS (Caso 6).

Nos casos com decisões desfavoráveis às providências cautelares, os tribunais dão relevo ao cumprimento dos limiares legais de risco (Casos 4 e 5) ou às medidas de minimização ou de 
compensação de impactes negativos (Casos 7 e 8) ou alteração do projeto (Caso 10), que consideram permitirem acautelar os danos ambientais mais graves e equilibrar os interesses económicos e ambientais envolvidos.

Quadro 9 - Elementos de fundamentação das decisões na $2^{\mathrm{a}}$ instância

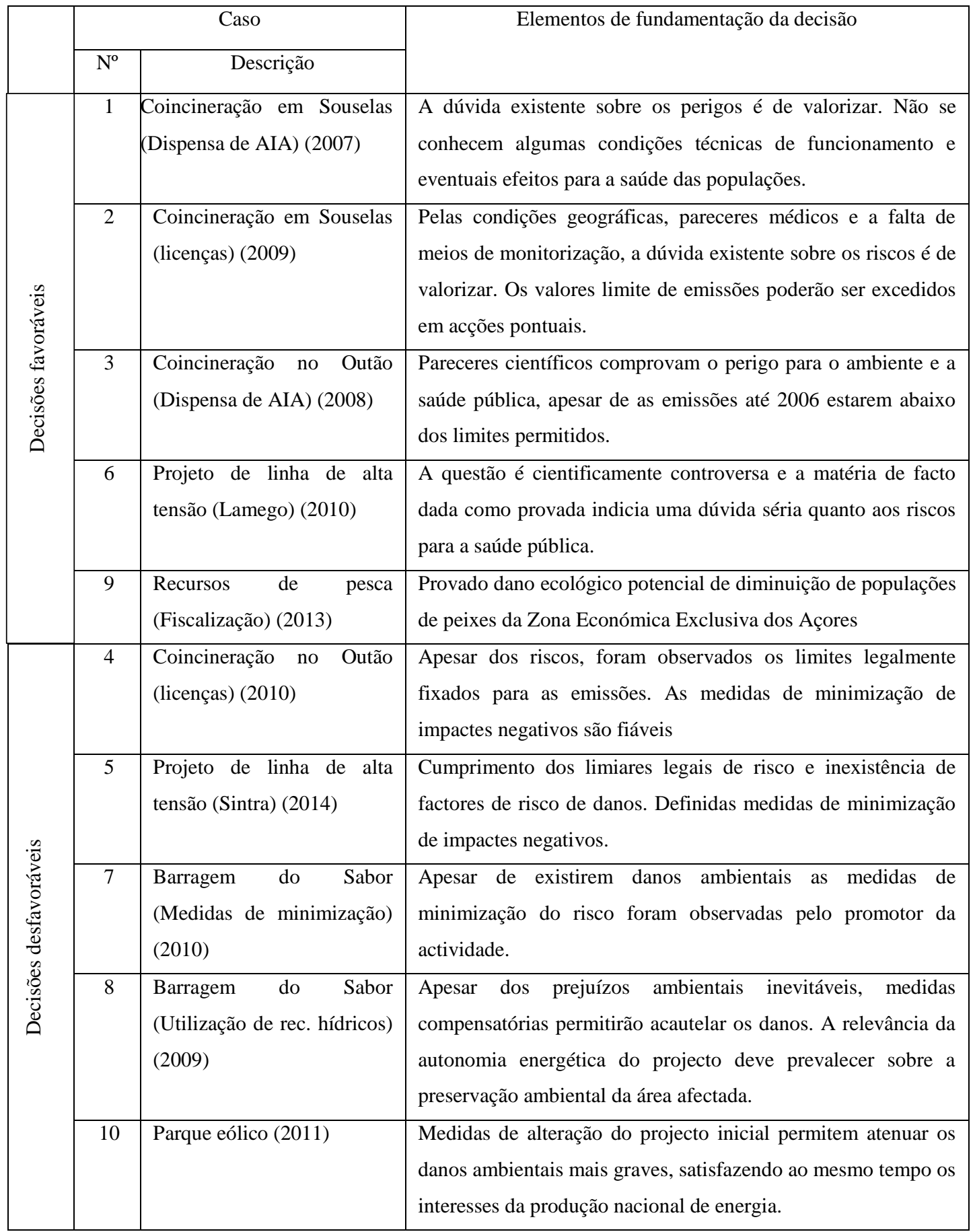

Fonte: Acórdãos dos Tribunais Centrais Administrativos (ver nas referências bibliográficas)

DINÂMIA'CET - IUL, Centro de Estudos sobre a Mudança Socioeconómica e o Território

do Instituto Universitário de Lisboa (ISCTE-IUL)

Sala 2W4 - D | ISCTE-IUL - Av. das Forças Armadas

1649-026 Lisboa, PORTUGAL

Tel. (+351) 210464031 - Extensão 293101 | E-mail: dinamia@iscte-iul.pt | www.dinamiacet.iscte-iul.pt 


\section{Avaliação e gestão dos riscos não comprovados: \\ Estudo de casos da aplicação do princípio da precaução em Portugal}

Constata-se que, contrariamente ao que sucede nos casos em que está em causa a dispensa da realização de Avaliação de Impacte Ambiental (AIA) na fábrica de Souselas e na do Outão (Casos 1 e 3), em que quer o TCAN quer o TCAS confirmam as decisões da instância anterior, favoráveis às providências cautelares, já nos casos em que é requerida a suspensão das licenças concedidas àquelas fábricas (Casos 2 e 4), enquanto o TCAS mantém a decisão da instância anterior, desfavorável à providência cautelar, o TCAN, perante recurso similar, altera o sentido da decisão da instância anterior (passa a favorável), valorizando agora a dúvida sobre os riscos. Também em relação aos projetos de linhas de alta tensão, perante riscos de natureza idêntica, o sentido das decisões é diferente para o TCAS (Caso 5) e o TCAS (Caso 6).

Nos casos com decisões desfavoráveis às providências cautelares, os tribunais dão relevo ao cumprimento dos limiares legais de risco (Casos 4 e 5) ou às medidas de minimização ou de compensação de impactes negativos (Casos 7 e 8) ou alteração do projeto (Caso 10), que consideram permitirem acautelar os danos ambientais mais graves e equilibrar os interesses económicos e ambientais envolvidos.

Nos acórdãos dos Casos 4 (co-incineração), 5 (linha de alta tensão) e 7 (barragem), o TCAS fundamenta as suas decisões com a aplicação do princípio da prevenção, que considera constituir suporte das Avaliações de Impacte Ambiental e das Declarações de Impacte Ambiental efectuadas. No Caso 4, o TCAS refere que, contrariamente à prevenção, a precaução significa a "aceitação de todo e qualquer risco", mas, assim, está a desconsiderar a proporcionalidade essencial do princípio da precaução.

\section{$\underline{3}^{\mathrm{a}}$ instância}

As decisões do STA foram, nos casos analisados, sempre desfavoráveis às providências cautelares (Quadro 10).

O STA, que considera, em geral, a matéria de facto relativa ao reconhecimento do perigo em concreto e à ponderação de interesses, fora dos seus poderes de cognição, limitando o seu papel à apreciação do cumprimento das regras de fixação dos factos que as anteriores instâncias julgaram, vem, no entanto, contrariar as decisões da instância anterior nos casos 1, 2, 3, 6 e 9. Quando menciona o princípio da precaução (nos Casos 2, 4, 5, 6 e 7), o STA não considera válida a sua aplicação por entender tratar-se de situações de meras conjecturas de risco não provadas. A posição do STA perante este princípio não surge, no entanto, com clareza. Se o STA refere também o princípio da precaução como um princípio geral de protecção ambiental que deve ser entendido apenas como orientação política e legislativa dos Estados no contexto da 


\section{Avaliação e gestão dos riscos não comprovados: \\ Estudo de casos da aplicação do princípio da precaução em Portugal}

prossecução dos interesses públicos em geral, alude, nos Casos 5 e 6, à tomada de medidas para acautelar os riscos e ao cumprimento dos limites de risco definidos legalmente, referindo estes como reflectindo as "exigências" da precaução.

Reconhecendo embora, em alguns destes casos, a falta de conhecimento sobre questões relevantes para a decisão e a dificuldade na obtenção de provas indubitáveis quanto aos perigos, considera ser necessário dispor de provas concretas e não reconhece o papel do princípio da precaução nas situações de dúvida sobre os riscos (como refere no Caso 7), quando é a estas situações que este princípio deve ser aplicado, com medidas mais ou menos restrictivas consoante a gravidade dos riscos.

Quadro 10 - Elementos de fundamentação das decisões na $3^{\mathrm{a}}$ instância

\begin{tabular}{|c|c|c|}
\hline \multicolumn{2}{|r|}{ Caso } & Elementos de fundamentação da decisão \\
\hline $\mathrm{N}^{\mathrm{o}}$ & Descrição & \\
\hline 1 & $\begin{array}{lll}\text { Coincineração em } & \text { Souselas } \\
(\text { Dispensa de AIA) } & (2007)\end{array}$ & $\begin{array}{l}\text { Só o licenciamento da actividade e não a dispensa de AIA } \\
\text { poderá ser o antecedente causal de possíveis danos. }\end{array}$ \\
\hline 2 & $\begin{array}{l}\text { Coincineração em } \quad \text { Souselas } \\
\text { (licenças) (2009) }\end{array}$ & $\begin{array}{l}\text { A situação de risco é uma mera conjectura.. Os danos } \\
\text { resultantes da suspensão da actividade são superiores aos que } \\
\text { resultariam da sua recusa. }\end{array}$ \\
\hline 3 & $\begin{array}{l}\text { Coincineração no Outão (Dispensa } \\
\text { de AIA) (2008) }\end{array}$ & $\begin{array}{l}\text { As licenças foram emitidas favoravelmente, pelo que o acto } \\
\text { em causa já nenhuns efeitos poderia produzir. }\end{array}$ \\
\hline 4 & $\begin{array}{l}\text { Coincineração no Outão (licenças) } \\
\text { (2010) }\end{array}$ & $\begin{array}{l}\text { A situação de risco é uma mera conjectura de verificação } \\
\text { apenas eventual. }\end{array}$ \\
\hline 5 & $\begin{array}{l}\text { Projeto de linha de alta tensão } \\
\text { (Sintra) (2014) }\end{array}$ & $\begin{array}{l}\text { Não existem provas de perigo e foram adoptadas medidas } \\
\text { para acautelar os riscos. }\end{array}$ \\
\hline 6 & $\begin{array}{l}\text { Projeto de linha de alta tensão } \\
\text { (Lamego) (2010) }\end{array}$ & $\begin{array}{l}\text { Não existem provas, mesmo sumárias, de perigo. Não } \\
\text { bastam dúvidas sobre alegados perigos. Os limites legais de } \\
\text { risco foram cumpridos. }\end{array}$ \\
\hline 7 & $\begin{array}{l}\text { Barragem do Sabor (Medidas de } \\
\text { minimização) (2010) }\end{array}$ & Não existem provas da existência de perigo. \\
\hline 8 & $\begin{array}{l}\text { Barragem do Sabor (Utilização de } \\
\text { recursos hídricos) (2009) }\end{array}$ & $\begin{array}{l}\text { Escassez de elementos factuais seguros sobre os perigos e } \\
\text { com natureza de mera conjectura. }\end{array}$ \\
\hline 9 & $\begin{array}{l}\text { Recursos de pesca (Fiscalização) } \\
(2013)\end{array}$ & $\begin{array}{l}\text { A protecção dos interesses dos pescadores portugueses não é } \\
\text { regulada pelas normas de fiscalização da Zona Económica } \\
\text { Exclusiva. }\end{array}$ \\
\hline 10 & Parque eólico (2011) & - \\
\hline
\end{tabular}

Fonte: Acórdãos do Supremo Tribunal Administrativo (ver nas referências bibliográficas) 


\subsection{Discussão. Aplicação do quadro de análise}

\section{(i) Natureza dos riscos}

Com base nos critérios de gravidade potencial dos riscos, apresentados na secção 4.1, e a partir da informação disponível nos acórdãos, concluiu-se quanto à natureza dos riscos em cada área de atividade como se indica no Quadro 11.

Quadro 11 - Nível de gravidade potencial dos riscos por área de atividade

\begin{tabular}{|l|c|c|c|c|c|}
\hline Área de atividade & $\begin{array}{c}\text { Relevância dos } \\
\text { danos potenciais }\end{array}$ & $\begin{array}{c}\text { Dispersão } \\
\text { geográfica }\end{array}$ & $\begin{array}{c}\text { Persistência } \\
\text { no tempo }\end{array}$ & $\begin{array}{c}\text { Relevância dos } \\
\text { Interesses envolvidos }\end{array}$ & $\begin{array}{c}\text { Gravidade } \\
\text { dos riscos }\end{array}$ \\
\hline Co-incineração & Alta & Alta & Alta & Alta & Alta \\
\hline Linhas de energia & Alta & Moderada & Alta & Moderada & Moderada \\
\hline Barragem & Moderada & Moderada & Alta & Alta & Moderada \\
\hline Recursos de pesca & Moderada & Alta & Alta & Alta & Moderada \\
\hline Parque eólico & Moderada & Moderada & Alta & Alta & Moderada \\
\hline
\end{tabular}

(ii) Informação utilizada, nível de exigência de prova e nível de severidade das medidas de precaução

As fontes de informação a que as partes envolvidas recorreram, nos vários processos, na procura dos factos justificativos das suas decisões são múltiplas, geralmente estudos ou pareceres técnicos e económicos. Os tribunais referem-se igualmente em geral, nas suas sentenças e acórdãos, aos mesmos factos mencionados pelas partes.

Todavia, são frequentemente mencionadas quer a falta de conhecimento quer as incertezas existentes em relação à apreciação dos perigos e à ponderação dos interesses, embora não sejam apresentadas nem a análise das incertezas, variáveis consoante os casos, nem a análise da respectiva relevância.

Sendo as posições, em cada caso, naturalmente contrárias entre as partes, a fundamentação respectiva apresenta divergências, quer em relação à existência ou não de perigos, quer aos resultados da ponderação de interesses. O princípio da precaução é geralmente invocado explicitamente pelas entidades que defendem a concessão das providências cautelares, enquanto as entidades promotoras das actividades económicas apenas mencionam o princípio da precaução para contra-argumentarem as posições das partes contrárias.

O estudo realizado, com o apoio do quadro de análise elaborado, permitiu constatar as posições diferenciadas entre os tribunais nas diferentes instâncias, com argumentos 


\section{Avaliação e gestão dos riscos não comprovados: \\ Estudo de casos da aplicação do princípio da precaução em Portugal}

contraditórios perante o mesmo caso ou perante casos semelhantes, reconhecendo os perigos mas atribuindo-lhes diferentes níveis de gravidade, exigindo diferentes níveis de prova ou dando prioridade a diferentes interesses. Atenda-se, por exemplo, à posição quanto à suficiência do cumprimento de limiares legais de risco ou da implementação de medidas de minimização de impactos negativos para evitar os perigos para a saúde humana ou para o ambiente.

A análise da fundamentação dos tribunais permite verificar que níveis de exigência de prova mais baixos parecem estar associados à aplicação "forte" da precaução e níveis de exigência de prova mais altos à aplicação "fraca" da precaução, tal como é considerado no quadro de análise ${ }^{14}$.

Além das discordâncias na apreciação e na decisão sobre os casos, parece verificar-se alguma falta de clareza na aplicação do conceito de precaução por algumas partes e por alguns tribunais que, nalguns casos, ao mesmo tempo que não aplicam o princípio da precaução, reconhecem existir dificuldade na obtenção de conhecimento sobre questões relevantes para a decisão. Verifica-se ainda alguma confusão com o conceito de prevenção, quanto ao nível de esclarecimento das incertezas e à definição dos riscos envolvidos como riscos comprovados ou não ${ }^{15}$.

As posições das partes e as decisões dos tribunais que são favoráveis às providências cautelares têm como fundamentação a aplicação do princípio da precaução, de uma forma em geral explicita mas em alguns casos implicitamente pela referência à irreversibilidade dos danos potenciais, ao desconhecimento e à incerteza sobre os perigos ou à necessidade da inversão do ónus da prova para os promotores da actividade de risco.

As partes e os tribunais mencionam o princípio da precaução também como suporte de algumas decisões que são desfavoráveis às providências cautelares, associado ao cumprimento de limites legais de risco ou de medidas de minimização de impactes negativos. De acordo com o quadro de análise apresentado na secção 4, trata-se de casos em que os tribunais aplicam o princípio da precaução, explicita ou implicitamente, na sua interpretação ou versão "fraca", a que está associado um nível de exigência de prova considerado moderado e que não implica a suspensão da atividade com risco, por contraste com os casos em que se valorizam as dúvidas sobre os

\footnotetext{
${ }^{14} \mathrm{Um}$ mais completo esclarecimento quanto à caracterização dos riscos e às limitações de conhecimento existentes na apreciação dos diferentes casos permitiria efectuar uma análise mais rigorosa dos níveis de exigência de prova pelos tribunais e a sua relação com os níveis de aplicação da precaução.

${ }^{15}$ Nas situações em que existe evidência científica firme sobre os riscos, as medidas restritivas deverão ser tomadas numa base preventiva, não de precaução.
} 
riscos além de quaisquer outras medidas de protecção que possam ter sido estabelecidas, que correspondem à aplicação do princípio da precaução na sua versão "forte".

Finalmente, nos restantes casos, as partes e os tribunais não aplicam o princípio da precaução porque consideram não existir qualquer perigo de danos.

No Quadro 12 indica-se o nível de aplicação do princípio da precaução pelos tribunais em todos os casos analisados, permitindo constatar as divergências verificadas entre as diferentes instâncias. Inclui-se neste quadro o nível de gravidade potencial dos riscos por área de atividade (ver Quadro 14) de modo a permitir concluir, na secção seguinte, sobre a proporcionalidade das medidas de precaução.

Procurando uma síntese do sentido geral das decisões dos tribunais das instâncias inferiores, e apesar das divergências existentes na fundamentação e na decisão em alguns casos, parece possível constatar uma maior propensão para decisões favoráveis à aceitação de providências cautelares (o que corresponde à aplicação da precaução na sua versão mais severa) nos casos em que poderá estar em causa a saúde humana (nas áreas da co - incineração de resíduos e das linhas de energia de alta tensão). Nos casos em que os riscos mais relevantes são relativos ao ambiente natural (barragem e parque eólico), os tribunais decidem contra a aceitação de providências cautelares, procurando assegurar a prossecução das atividades e dos interesses económicos. Finalmente, no caso que envolve a preservação dos recursos de pesca, a decisão a favor da providência cautelar surge ao mesmo tempo para defesa dos ecossistemas marinhos e dos interesses económicos das populações de pescadores e da região.

Quadro 12 - Nível de gravidade potencial dos riscos e nível de aplicação da precaução

\begin{tabular}{|c|c|c|c|c|c|}
\hline \multirow[t]{2}{*}{ Caso $n^{\circ}$} & \multirow[t]{2}{*}{ Área de atividade } & \multirow{2}{*}{$\begin{array}{c}\text { Nível de gravidade } \\
\text { dos riscos }\end{array}$} & \multicolumn{3}{|c|}{ Nível de aplicação da precaução } \\
\hline & & & TAFs & TCAs & STA \\
\hline 1 & \multirow{4}{*}{ Coincineração } & \multirow{4}{*}{ Alta } & Forte & Forte & - \\
\hline 2 & & & Fraco & Forte & - \\
\hline 3 & & & Forte & Forte & - \\
\hline 4 & & & Fraco & Fraco & - \\
\hline 5 & \multirow[t]{2}{*}{ Linha de alta tensão } & \multirow[t]{2}{*}{ Moderada } & Fraco & Fraco & Fraco \\
\hline 6 & & & - & Forte & Fraco \\
\hline 7 & \multirow[t]{2}{*}{ Barragem do Sabor } & \multirow[t]{2}{*}{ Moderada } & Fraco & Fraco & - \\
\hline 8 & & & - & Fraco & - \\
\hline 9 & Recursos de pesca & Moderada & Forte & Forte & - \\
\hline 10 & Parque eólico & Moderada & Fraco & Fraco & \\
\hline
\end{tabular}

Nota: “-“ nas situações em que o princípio da precaução não foi aplicado 
Porém, as decisões do Supremo Tribunal Administrativo, sempre desfavoráveis às providências cautelares, parecem representar, finalmente, a prioridade atribuída aos interesses económicos e à riqueza do País, em desfavor de interesses ambientais de âmbito local ou regional.

Uma outra questão poderia colocar-se a este respeito: a de avaliar qual a importância atribuída, na resolução dos litígios, à aplicação dos princípios jurídicos (como o princípio da precaução), face à que é atribuída à aplicação das políticas do Governo.

Neste contexto, as questões relativas à aceitabilidade social dos riscos (que deverão traduzir-se nos níveis de exigência de prova dos decisores) terão de ser tidas em conta, dada a sua relevância para a tomada de decisão pelos tribunais.

\section{(iii) Proporcionalidade das medidas de precaução}

Finalmente, efectuou-se uma análise da proporcionalidade das decisões de precaução de modo a concluir se as medidas mais restritivas, isto é, neste estudo, as decisões favoráveis às providências cautelares, que suspendem a execução das actividades de risco (e que traduzem níveis de precaução "forte"), correspondem ou não aos casos em que a gravidade dos perigos potenciais é maior, e contrariamente para as decisões desfavoráveis (que traduzem níveis de precaução "fraca" ou inexistente).

A análise efectuada permite considerar que as medidas de precaução aplicadas são proporcionais em relação ao nível de gravidade dos riscos em 5 dos 8 casos em que o princípio da precaução foi aplicado na primeira instância (TAFs) (co-incineração - 2, linha de alta tensão - 1, barragem - 1 e parque eólico - 1), em 7 dos 10 casos na segunda instância (TCAs) (coincineração - 3, linha de alta tensão - 1, barragem - 2, parque eólico - 1) e nos 2 casos em que se considerou o princípio da precaução aplicado na terceira instância (STA) (Quadro 13).

Estes resultados, que traduzem naturalmente as divergências nas decisões dos tribunais referidas ao longo deste estudo, talvez permitam concluir, sem se esquecerem as limitações da análise, que, apesar da diversidade existente no entendimento quanto à natureza dos riscos e à interpretação e aplicação do princípio da precaução, as decisões dos tribunais surgem maioritariamente proporcionais ao nível de protecção requerido. 
Quadro 13 - Proporcionalidade das medidas de precaução

\begin{tabular}{|c|c|c|c|c|}
\hline \multirow[t]{2}{*}{ Caso $\mathrm{n}^{\circ}$} & \multirow[t]{2}{*}{ Área de atividade } & \multicolumn{3}{|c|}{ Proporcionalidade das medidas de precaução } \\
\hline & & TAFs & TCAs & STA \\
\hline 1 & \multirow{4}{*}{ Coincineração } & Sim & Sim & - \\
\hline 2 & & Não & Sim & - \\
\hline 3 & & Sim & Sim & - \\
\hline 4 & & Não & Não & - \\
\hline 5 & \multirow{2}{*}{$\begin{array}{l}\text { Linha de alta } \\
\text { tensão }\end{array}$} & Sim & Sim & Sim \\
\hline 6 & & - & Não & Sim \\
\hline 7 & \multirow{2}{*}{$\begin{array}{c}\text { Barragem do } \\
\text { Sabor }\end{array}$} & Sim & Sim & - \\
\hline 8 & & - & Sim & - \\
\hline 9 & Recursos de pesca & Não & Não & - \\
\hline 10 & Parque eólico & Sim & Sim & \\
\hline
\end{tabular}

Nota: “-“ nas situações em que o princípio da precaução não foi aplicado

\section{CONCLUSÕES}

A análise efectuada aos casos judiciais apresentados neste estudo permitiu conhecer o modo como os tribunais lidam com os riscos não comprovados em Portugal.

Foi possível constatar que o princípio da precaução está bem inserido no Direito Ambiental em Portugal, sendo invocado pelos juízes em várias instâncias, com as decisões favoráveis às providências cautelares tendo por base a sua aplicação.

No entanto, enquanto alguns tribunais são claros na invocação deste princípio, outros são cautelosos dado o estatuto incerto que apresenta, e, por vezes, fazem-no apenas como argumento auxiliar para apoiar uma decisão tomada com base em outras fontes de direito aplicáveis, como as associadas à definição de limiares de risco ou de medidas de minimização de impactes negativos ${ }^{16}$.

As dificuldades dos decisores podem constatar-se com o recurso pelos tribunais a informação relevante sobre os riscos mas por vezes pouco clara, sem análise das incertezas e com insuficiente abrangência, fundamentação e credibilização da informação utilizada. As análises comparadas de riscos e de benefícios como suporte para uma adequada ponderação de interesses são também muitas vezes insuficientes e realizadas a partir de critérios não explicitados, que poderão envolver escolhas económicas, sociais e políticas.

\footnotetext{
${ }^{16}$ Nestas situações, não resulta evidente se as decisões dos tribunais reflectem a aplicação do princípio da precaução na sua versão "fraca" ou se baseiam em acção preventiva, a qual é conceptualmente adequada para lidar com riscos comprovados.
}

DINÂMIA'CET - IUL, Centro de Estudos sobre a Mudança Socioeconómica e o Território

do Instituto Universitário de Lisboa (ISCTE-IUL)

Sala 2W4 - D | ISCTE-IUL - Av. das Forças Armadas

1649-026 Lisboa, PORTUGAL

Tel. (+351) 210464031 - Extensão 293101 | E-mail: dinamia@iscte-iul.pt | www.dinamiacet.iscte-iul.pt 


\section{Avaliação e gestão dos riscos não comprovados: \\ Estudo de casos da aplicação do princípio da precaução em Portugal}

Os resultados obtidos neste estudo permitem concluir, no mesmo sentido de outros estudos teóricos e empíricos realizados noutros países, que, de modo a contrariar o recurso a informação pouco clara e insuficiente quanto às incertezas existentes, levando à percepção de níveis diferenciados de gravidade dos riscos e conduzindo a decisões contraditórias, será desejável que a regulamentação do princípio da precaução possa vir a dispor de requisitos e de critérios mais explícitos quanto ao esclarecimento sobre os riscos e a ponderação de interesses, nas diferentes áreas de actividade, e quanto à proporcionalidade das decisões.

Em particular, nas disputas nas áreas ambientais as decisões judiciais deverão ser mais exigentes na apreciação técnica dos riscos e na ponderação dos interesses envolvidos e menos dependentes da perpectiva subjetiva dos juízes.

Neste contexto, será muito importante que os tribunais possam dispor do apoio técnico e de orientação de uma expertise científica de qualidade relativamente à análise da informação ambiental e económica.

Assim, no apoio aos decisores, e tendo em vista contribuir para uma melhor avaliação e operacionalização futura das decisões de precaução, será desejável:

- Procurar conhecer a informação mais completa possível com os melhores dados científicos disponíveis sobre os danos ambientais potenciais e sobre os efeitos económicos e sociais: âmbito, magnitude, escala temporal, valor estimado, reversibilidade ou não, ligação com outros impactes

- Quando a informação é incompleta ou indisponível torná-lo claro, justificando as escolhas feitas ou porque não se realizam mais estudos, considerar alternativas de acção com menos incerteza, listar as provas científicas mais relevantes

- Procurar considerar níveis mínimos de prova científica, com base na avaliação da percepção e da aceitabilidade social do risco

- Adequar as medidas de precaução a seleccionar à natureza dos riscos e depois de devidamente ponderados os múltiplos interesses em jogo.

Será assim possível uma maior transparência, ultrapassando alguma discricionariedade atualmente existente na fundamentação de muitas posições dos tribunais, gerando maior previsibilidade, com a consequente redução de disputas em tribunal e a inerente poupança de tempo e de custos.

Com a sugestão de esquemas procedimentais consistentes e de orientações sobre o tipo de medidas requeridas (com proporcionalidade), a evolução da jurisprudência permitirá uma maior clarificação da aplicação da precaução para as diferentes naturezas de risco, no contexto dos

DINÂMIA'CET - IUL, Centro de Estudos sobre a Mudança Socioeconómica e o Território

do Instituto Universitário de Lisboa (ISCTE-IUL)

Sala 2W4 - D | ISCTE-IUL - Av. das Forças Armadas

1649-026 Lisboa, PORTUGAL

Tel. (+351) 210464031 - Extensão 293101 | E-mail: dinamia@iscte-iul.pt | www.dinamiacet.iscte-iul.pt 
valores políticos, económicos, sociais e culturais vigentes. Deste modo, poderá tornar-se mais efetiva a comparação entre diferentes medidas de precaução e a própria validade legal das medidas de precaução.

\section{REFERÊNCIAS BIBLIOGRÁFICAS}

ALFRED, J. (2012), "Climate change uncertainty, irreversibility and the precautionary principle", Cambridge Journal of Economics, 36, 1051-1072.

ARAGÃO, A. (2013), “Aplicação nacional do princípio da precaução”, Colóquios 2011-2012, Associação dos Magistrados da Jurisdição Administrativa e Fiscal de Portugal, 159-185.

AVEN, T. (2011), "On diferente types of uncertainties in the context of the precautionary principle”, Risk Analysis, v. 31, n. 10.

AVEN, T. \& RENN, O. (2010), "Risk Management and Governance. Concepts, Guidelines and Applications", Springer, Heidelberg.

BEVAN, J.P. (2009), "Determining significance in environmental impact assessment: A review of impacts upon the socio-economic and water environments", School of Environmental Sciences, University of East Anglia, University Plain, Norwich, 79 s.

BOCCHI, M. (2016), "The Reshaping of the Precautionary Principle by International Courts: Judicial Dialogue or Parallel Monologues?, Geneva Jean Monnet working paper 02, Centre d'Études Juridiques Européennes/Université de Genève.

BOUDER, F., SLAVIN, D. \& LOFSTEDT, R. (2007), "A New Framework for Risk Management", Earthscan.

CANOTILHO, J.J. G. (1995), "Protecção do Ambiente e direito de propriedade (Crítica de jurisprudência ambiental)", Coimbra.

CE (2000), "Comunicação da Comissão sobre o Princípio da Precaução", COM (2000) - 1, Comissão Europeia, Bruxelas. 
CPP (2010), "La décision publique face à l'incertitude. Clarifier les règles, améliorer les outils “, Comité de la Précaution et de la Prévention, Ministère de 1’Ecologie, de 1'Energie, du Développement Durable et de la Mer, Mars, Paris.

COONEY, R. (2005), Biodiversity and the Precautionary Principle: Risk and Uncertainty in Conservation and Sustainable Use, Earthscan, London.

DE SADELEER, N. (2009), "The precautionary principle as a device for greater environmental protection: lessons from EC courts", Review of European, Comparative and International Law, $18(1), 3-25$.

DE SADELEER, N. (2006), "The precautionary principlein EC Health and Environmental Law”, European Law Journal, 12:2, 139.

EC (2011), "Considerations on the application of the Precautionary Principle in the chemicals sector. Final Report”, European Commission, Milieu Ltd, T.M.C. Asser Instituut, PACE, DG Environment.

EEA (2013), "Late lessons from early warnings: science, precaution, innovation”, European Environment Agency, EEA Report, n. 1.

ETIENNE, J.-C. (2009), "Rapport sur le principe de précaution : bilan de son application quatre ans après sa constitutionnalisation" (Compte rendu de l'audition publique du ler octobre. Office Parlementaire d'evaluation des choix scientifiques et technologiques).

GARNETT, K. e PARSONS, D. J. (2017), "Multi-case review of the application of the precautionary principle in European Union law and case law", Risk Analysis, Volume 37, Issue 3, March, 502-516.

GILBOA, I. e SCHMEIDLER, D. (1989), "Maximin Expected Utility with a Non Unique Prior". Journal of Mathematical Economics, 18, 141-153.

GODARD, O. (2010), "Faisons meilleur usage du principe de précaution!“, Constructif, n. 27, nov. 
GODARD, O. (2005), "Le principe de précaution et la proportionnalité face à l'incertitude scientifique“ em Conseil d'État, Rapport public 2005 - Responsabilité et socialisation du risque, La Documentation Française, Paris.

GOLLIER, C. e TREICH, N. (2003), "Decision-making under scientific uncertainty: the economics of the precautionary principle", Journal of Risk and Uncertainty 27 (1), 77-103.

GOMES, C. A. (2013), "Direito do ambiente: anotações jurisprudenciais dispersas", Instituto de Ciências Jurídico-Políticas, Faculdade de Direito da Universidade de Lisboa.

GONÇALVES, V. (2013), "Critical approach of the use of economic models in precautionary risk management", European Journal of Risk Regulation, vol. 4, Dec., 335-345.

HARREMOES, P., GEE, D., MACGARVIN, M., STIRLING, A., KEYS, J., WYNNE, B. \& VAZ., S. eds. (2002), The Precautionary Principle in the 20th Century: Late Lessons from Early Warnings, Earthscan Publications, London.

IRGC (2008), An Introduction to the IRGC Risk Governance Framework. Policy Brief, International Risk Governance Council, Geneva. 2008.

IVERSON, T e PERRINGS, C. (2012), "Precaution and proportionality in the management of global environmental change", Global Environmental Change 22 (1), 161-177.

JALAVA, K., POLONEN, I., HOKKANEN, P. e KUITUNEN, M. (2013), "The precautionary principle and management of uncertainties in EIAs - analysis of waste incineration cases in Finland“, Impact Assessment and Project Appraisal, Volume 31, Issue 4, 280-290.

KAHNEMAN, D. \& TVERSKY, A. (1979), "Prospect theory: an analysis of decision under risk", Econometrica, 47(2), 263-91.

KLINKE A., RENN O. (2010), “Risk Governance: Contemporary and Future Challenges” in: Eriksson J., Gilek M., Rudén C. (eds), Regulating Chemical Risks, Springer, Dordrecht.

DINÂMIA'CET - IUL, Centro de Estudos sobre a Mudança Socioeconómica e o Território do Instituto Universitário de Lisboa (ISCTE-IUL)

Sala 2W4 - D | ISCTE-IUL - Av. das Forças Armadas

Tel. (+351) 210464031 - Extensão 293101 | E-mail: dinamia@iscte-iul.pt | www.dinamiacet.iscte-iul.pt 
KLINKE, A. RENN, O. (2012), "Adaptive and integrative governance on risk and uncertainty", Journal of Risk Research, Volume 15, 3, 273-292.

LOFSTEDT, R., (2014), "The precautionary principle in the EU: Why a formal review is long overdue", Risk Management, 16(3), 137-163.

MYERS, N. \& RAFFENSPERGER, C. (2005), Precautionary tools for reshapping environmental policy, Island Press, Washington.

NOIVILLE C. (2015), "Principe de precaution", Dictionnaire critique de l'expertise. Santé, travail, environnement”. Presses de Sciences Po (P.F.N.S.P.) 240-249.

O' CONNOR, M e SPASH, C. (2001), Environmental valuation in Europe - EVE Project report, DG-XII, EC.

OECD (2003), Emerging systemic risks. Final report to the OECD Futures Project, Paris.

OCDE, 1997, Évaluation économique des politiques et projets environnementaux, OCDE, Paris. OLIVEIRA, C. M., JUNIOR, J. W. Z., ESPÍNDOLA, I. B. (2016), "O tribunal arbitral como instrumento jurídico alternativo de solução de conflitos hídricos no Brasil", Ambiente \& Sociedade, v. XIX, n. 1, jan.-mar., 147-164.

PEEL, J. (2009), "Interpretation and Application of the Precautionary Principle: Australia's Contribution", Review of European, Comparative and International Law, V. 18, Issue 1 , April, $11-25$.

RANDALL, A. (2009), "We Already Have Risk Management - Do We Really Need the Precautionary Principle?". International Review of Environmental and Resource Economics, Vol. 3, 1, 39-74.

RENN, O. (2008), Risk governance: coping with uncertainty in a complex world, Earthscan, London.

RENN, O., DREYER, M., KLINKE, A., LOSERT, C., STIRLING, A., VAN ZWANENBERG, P., MULLER-HEROLD, U., MOROSINI, M. e FISHER, E. (2009), "The Application of the 
Precautionary Principle in the European Union" em Precautionary risk appraisal and management. An orientation for meeting the precautionary principle in the European Union, Europaeischer Hochschulverlag.

ROGERS, M. D. (2011), "Risk management and the record of the precautionary principle in EU case law, Journal of Risk Research, Vol. 14, 4, Abril, 467-484.

SACHS, N. M. (2011), "Rescuing the Strong Precautionary Principle from its Critics", University of Illinois Law Review, Vol. 2011, p. 1285, 2011

SAVAGE, L. (1954), The foundations of statistics, Revised and enlarged edition (1972) Dover, New York.

SECRETARIAT OF THE CONVENTION ON BIOLOGICAL DIVERSITY (2000), Cartagena Protocol on Biosafety to the Convention on Biological Diversity: text and annexes. Secretariat of the Convention on Biological Diversity, Montreal, Canada.

SEHN (2009), Advancing the precautionary agenda. Science \& Environmental Health Network, Feb.

SEHN (1998), Wingspread Consensus Statement on the Precautionary Principle. Science \& Environmental Health Network.

STIRLING, A. (2017), "Precautionary appraisal as a response to risk, uncertainty, ambiguity and ignorance", em Spash, C. L. (ed.) Routledge handbook of ecological economics, Routledge international handbooks, Abingdon, 267-277.

STIRLING, A. (2007), "Risk assessment in science: Towards a more constructive policy debate". EMBO Reports 8: 309-15.

STIRLING, A. e MAYER, S. (2005), "Confronting Risk and Precaution: a Multi-Criteria Mapping of a GM Crop" em Getzner, M. (ed.), Developing Alternatives for Valuing Nature. Routledge, London. 
STOKES, E. (2008), “The EC courts' contribution to refining the parameters of precaution", Journal of Risk Research, Vol. 11, Issue 4, 491-507.

TOSUN, J. (2013), «How the EU handles uncertain risks: understanding the role of the precautionary principle”, Journal of European Public Policy, Vol. 20, 2013 - Issue 10

UNCED (1992), Declaração do Rio sobre o Ambiente e o Desenvolvimento. Conferência das Nações Unidas sobre o Ambiente e o Desenvolvimento, Jun 14, 31 ILM 874, 879.

WIENER, J. B., ROGERS, M. D., HAMMITT, J. K. and SAND, P. H. eds. (2011), The Reality of Precaution: Comparing Risk Regulation in the United States and Europe, RFF Press/Earthscan.

WIENER, J. e M. ROGERS, 2002, Comparing precaution in the United States and in Europe, Journal of Risk Research 5 (4), 317-349.

ZANDER, J. (2010), The Application of the Precautionary Principle in Practice: Comparative Dimensions, Cambridge University Press.

\section{LEGISLAÇÃO}

CPTA (2002), Código de Processo nos Tribunais Administrativos. Aprovado pela Lei $\mathrm{n}^{\circ}$. 15/2002 de 22 de Fevereiro, com alterações posteriores.

Lei nº58/2005 de 29 de Dezembro (Lei da Água)

Decreto Lei $n^{\circ}$ 173/2008 de 26 de Agosto do Ministério do Ambiente, do Ordenamento do Território e do Desenvolvimento Regional (Licenciamento ambiental)

Lei n²7/2006 de 3 de Julho (Lei de Bases da Protecção Civil)

Decreto Lei $\mathrm{n}^{\circ}$ 142/2008 de 24 de Julho do Ministério do Ambiente, do Ordenamento do Território e do Desenvolvimento Regional (Regime Jurídico da Conservação da Natureza e da Biodiversidade) 


\section{OS CASOS}

- Município de Coimbra v. Cimpor/ Min. Ambiente, Proc. 758/06.3BECBR

- A e B ... v. Cimpor/ Min. Ambiente, Proc. 582/08.9BECBR

- Municípios de Setúbal, Palmela e Sesimbra v. Min. Ambiente e Economia, Proc. 994/06

- Municípios de Setúbal, Palmela e Sesimbra v. Min. Ambiente e Secil, Proc. 994/06-B

- Freg. Monte Abraão v. Min. Economia e A ... (REN), Proc. 04613/08

- Casal de proprietários v. Empresas A ... e B ..., Proc. 1722/07.OBEVIS

- Quercus e outros A ... v. EDP, Proc. 1266/08.3BELSB

- LPN e Quercus v. Instituto da Água, Proc. 387/08.7BEMDL-A

- Associações de Pescadores v. Min. Defesa, Proc. 05849/10

- Quercus v. Min. Ambiente, Município de ... e S ... (Soc. Elect.), Proc.6795/10 